\title{
Plant-Derived Nutraceuticals and Immune System Modulation: An Evidence-Based Overview
}

\author{
Antonella Di Sotto*(D), Annabella Vitalone*(D) and Silvia Di Giacomo \\ Department of Physiology and Pharmacology, Sapienza University of Rome, P.le Aldo Moro 5, 00185 Rome, \\ Italy; silvia.digiacomo@uniroma1.it \\ * Correspondence: antonella.disotto@uniroma1.it (A.D.S.); annabella.vitalone@uniroma1.it (A.V.); \\ Tel.: +39-064-9912-497 (A.D.S.); +39-064-9912-904 (A.V.)
}

Received: 31 July 2020; Accepted: 19 August 2020; Published: 22 August 2020

check for

\begin{abstract}
Immunomodulators are agents able to affect the immune system, by boosting the immune defences to improve the body reaction against infectious or exogenous injuries, or suppressing the abnormal immune response occurring in immune disorders. Moreover, immunoadjuvants can support immune system acting on nonimmune targets, thus improving the immune response. The modulation of inflammatory pathways and microbiome can also contribute to control the immune function. Some plant-based nutraceuticals have been studied as possible immunomodulating agents due to their multiple and pleiotropic effects. Being usually more tolerable than pharmacological treatments, their adjuvant contribution is approached as a desirable nutraceutical strategy. In the present review, the up to date knowledge about the immunomodulating properties of polysaccharides, fatty acids and labdane diterpenes have been analyzed, in order to give scientific basic and clinical evidence to support their practical use. Since promising evidence in preclinical studies, limited and sometimes confusing results have been highlighted in clinical trials, likely due to low methodological quality and lacking standardization. More investigations of high quality and specificity are required to describe in depth the usefulness of these plant-derived nutraceuticals in the immune system modulation, for health promoting and disease preventing purposes.
\end{abstract}

Keywords: immune system boosters; immunosuppressors; polysaccharides; fatty acids; labdane diterpenes; punicic acid; oleic acid; $\gamma$-linolenic acid; $\beta$-glucans; andrographolide

\section{Introduction}

Immunomodulators are defined as agents able to affect the immune response, which represents the set of reactions activated to protect the organism against infective agents, environmental injuries and illness; moreover, immune response can counteract the invasion of harmful native cells, such as precancerous and cancerous ones [1].

Immune response is mediated by a first line of defence, namely innate immunity (Figure 1), which is characterized by physical and biochemical barriers, alongside a non-specific cell-mediated immune response, including granulocytes, macrophages, natural killer cells and humoral elements, which cooperate to counteract pathogen infection and malignant transformation [2]. Moreover, an adaptive immunity is activated as a second defense line after a macrophage-mediated presentation of antigens to B lymphocytes, with the help of T lymphocytes; then, B cells can mediate the humoral immunity through the production of high-affinity antibodies and establish immunological memory [3]. Moreover, $\mathrm{T}$ lymphocytes can mediate cellular immunity after activation by cytokines released from helper $\mathrm{T}$ cells [2]. 


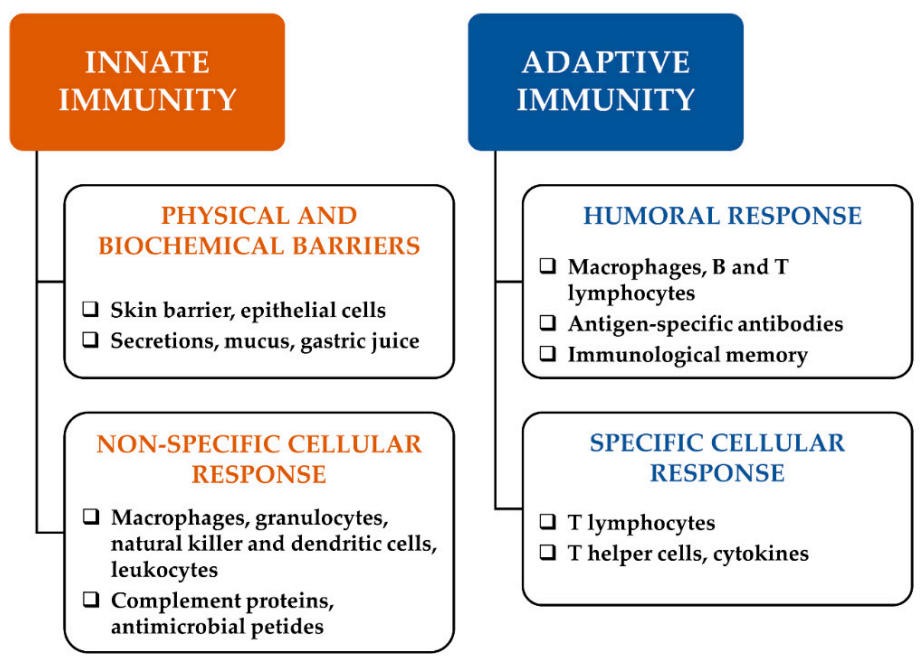

Figure 1. Responses involved in innate and adaptive immunity. Fast and nonspecific responses, occurring against all factor identified as nonself, are involved in innate immunity; conversely, adaptive immunity is a highly specific, complex and slow response mediated by $\mathrm{T}$ and B lymphocytes, which release antigen-specific antibodies and cytokines. Immunomodulators can directly affect innate and adaptive response or the factors involved, thus leading to immunostimulant or immunosuppressive effects.

Immunomodulating agents can affect immunity in a negative or positive manner, thus being categorized as suppressing or stimulant [4]. Particularly, immunosuppressors inhibit the activation of immune response or decrease the activity of its components, thus restoring normalcy. They are of interest in organ transplantations and in autoimmune disorders, wherein the immune system mistakenly activates an immune response against the own body tissues, leading to their destruction [4]. For instance, vitamin $\mathrm{D}$ has been shown to counteract the aberrant immune responses of systemic lupus erythematosus, without compromising the physiological defences and to produce benefits in atopic dermatitis too $[5,6]$.

Conversely, immunostimulants boost the endogenous immune defences, thus allowing one to restore or maintain the body homeostasis [4]. They can be usefully exploited as immunotherapeutic agents by individuals with immunocompromised conditions; however, they can represent suitable prophylactic strategies for healthy individuals or more susceptible subjects against viral infections [4]. In support, during the current SARS-CoV-2 pandemic, the trained immunity by vaccines, which induce heterologous protection, have been proposed as a rational strategy to boost antiviral defences and reduce susceptibility to infection [7].

A further group of immunomodulators is represented by immunoadjuvants, able to enhance immune response to vaccines without producing specific antigenic effects, and more recently approached as adjuvant pharmacological treatments, especially for viral infections and cancers [8-12].

Immune-associated disorders, including autoimmune diseases, viral or bacterial infections, and chronic diseases, are usually associated with acute inflammation, which represents a key component for the activation of immune response [13]. On the other hand, the chronicity of inflammatory response can negatively influence the immune function, affecting both innate immune cells and $\mathrm{T}$ and B lymphocytes, thus suggesting a possible usefulness of anti-inflammatory immunomodulators [13]. Accordingly, immunomodulatory agents, with antioxidant and anti-inflammatory activity, have attracted great attention as possible chemopreventive agents, due to their ability to counteract chronic inflammation, which provides favorable conditions for the transition from normal to cancer cell [14].

Furthermore, immunostimulants can act as adjuvant anticancer treatments, to counteract their immunosuppressive side-effects [14]. 
Growing evidence highlighted an important role of gut microbiome in the maintenance of immune function, and the disruption of the microbiome seems to have a role in disease development [15]. This intimate microbiome-immune system crosstalk suggests that boosting the resident microbiome, through pre/probiotic supplementations or suitable intervention for preventing disruption of microbial communities, can reinforce the immune defences, thus representing an alternative immunomodulatory strategy [16].

Several medicinal plants and phytochemicals are known since the ancient time for their ability to modulate the immune system function [17]. As major immunomodulatory mechanisms, they act especially as boosters of immune system, through the stimulation of both innate and adaptive humoral and cellular immunity (Table 1). However, further mechanisms, such as an interference with proinflammatory pathways and a modulation of the gut microbiome, have been reported [18-20].

Table 1. Some examples of bioactive constituents obtained from immunomodulatory plants, and their effect on immune function.

\begin{tabular}{|c|c|c|c|}
\hline Medicinal Plants & Phytochemicals & $\begin{array}{l}\text { Effect on Immune Function/Type of } \\
\text { Immunomodulation }\end{array}$ & References \\
\hline $\begin{array}{c}\text { Acacia catechu Willd. } \\
\text { heartwood }\end{array}$ & $\begin{array}{l}\text { Flavonoids, phenolic acids, } \\
\text { catechins }\end{array}$ & Antinflammatory activity/Immunoadjuvant & [21] \\
\hline Aloe vera (L.) Burm.f. & $\begin{array}{l}\text { Acemannan, } \\
\text { dihydrocoumarins }\end{array}$ & $\begin{array}{c}\text { Adaptive immunity } \\
\text { activation/Immunostimulant }\end{array}$ & [22-24] \\
\hline $\begin{array}{l}\text { Andrographis paniculata } \\
\text { (Burm.f.) Nees }\end{array}$ & $\begin{array}{l}\text { Diterpene lactones } \\
\text { (andrographolide) }\end{array}$ & $\begin{array}{l}\text { Modulation of innate and adaptive } \\
\text { immunity/Immunosuppressor }\end{array}$ & [25] \\
\hline $\begin{array}{l}\text { Artocarpus tonkinensis A. } \\
\text { Chev. Ex Gagnep }\end{array}$ & $\begin{array}{c}\text { Auronol glycosides } \\
\text { (maesopsin 4-O-glucoside and } \\
\text { alphitonin-4-O-glucoside) }\end{array}$ & $\begin{array}{l}\text { Inhibition of humoral and cellular adaptive } \\
\text { immunity/Immunosuppressor }\end{array}$ & [26] \\
\hline $\begin{array}{l}\text { Astragalus membranaceous } \\
\text { (Fisch.) Bge. }\end{array}$ & Polysaccharides & $\begin{array}{c}\text { Activation of cellular } \\
\text { immunity/Immunostimulant }\end{array}$ & [27] \\
\hline $\begin{array}{l}\text { Boswellia serrata Roxb. ex } \\
\text { Colebr }\end{array}$ & Boswellic acid & $\begin{array}{l}\text { Anti-anaphylactic and mast cell } \\
\text { stabilization/Immunosuppressor }\end{array}$ & [28] \\
\hline $\begin{array}{l}\text { Camellia sinensis (L.) } \\
\text { Kuntze }\end{array}$ & Polysaccharides & $\begin{array}{l}\text { Activation of immunoreactivity through the } \\
\text { modulation of gut } \\
\text { microbiome/Immunostimulant effect }\end{array}$ & {$[20,29]$} \\
\hline $\begin{array}{l}\text { Centella asiatica (L.) } \\
\text { Urban }\end{array}$ & Madecassoside & $\begin{array}{l}\text { Regulation the abnormal humoral and } \\
\text { cellular immunity/Immunosuppressor }\end{array}$ & {$[30]$} \\
\hline Curcuma longa $\mathrm{L}$. & Curcuminoids & $\begin{array}{l}\text { IL-10-mediated anti-inflammatory and } \\
\text { immunosuppressive } \\
\text { activity/Immunosuppressor }\end{array}$ & [31] \\
\hline $\begin{array}{l}\text { Echinacea purpurea (L.) } \\
\text { Moench }\end{array}$ & $\begin{array}{l}\text { Alkylamides, glycoproteins, } \\
\text { polysaccharides }\end{array}$ & $\begin{array}{l}\text { Activation of cellular immunity and } \\
\text { modulation of gut microbiome }\end{array}$ & [18] \\
\hline Glycyrrhiza glabra L. & $\begin{array}{l}\text { Triterpene saponins } \\
\text { (glycyrrhizin) }\end{array}$ & $\begin{array}{l}\text { Enhanced cellular immunity and } \\
\text { antinflammatory activity/Immunostimulant }\end{array}$ & [32] \\
\hline Hypoxis rooperi $\mathrm{T}$. Moore & $\begin{array}{l}\text { Phenolic glucosides } \\
\text { (hypoxoside) }\end{array}$ & $\begin{array}{c}\text { Antinflammatory } \\
\text { properties/Immunoadjuvant }\end{array}$ & [33] \\
\hline Ocimum sanctum $\mathrm{L}$. & $\begin{array}{c}\text { Monoterpenes (eugenol and } \\
\text { methyleugenol), } \\
\text { sesquiterpenes } \\
(\beta \text {-caryophyllene) }\end{array}$ & $\begin{array}{l}\text { Activation of innate and adaptive } \\
\text { immunity/Immunostimulant }\end{array}$ & [34] \\
\hline $\begin{array}{l}\text { Panax ginseng C.A. } \\
\text { Meyer }\end{array}$ & $\begin{array}{l}\text { Triterpene saponins } \\
\text { (ginsenosides) }\end{array}$ & $\begin{array}{l}\text { Adaptogen effects, stimulation of immune } \\
\text { systems via cytokine activation, modulation } \\
\text { of gut microbiome }\end{array}$ & {$[19,35,36]$} \\
\hline $\begin{array}{l}\text { Syzigium aromaticum (L.) } \\
\text { Merr. and L.M. Perry }\end{array}$ & $\begin{array}{l}\text { Monoterpenes (eugenol), } \\
\text { sesquiterpenes } \\
(\beta \text {-caryophyllene })\end{array}$ & $\begin{array}{l}\text { Activation of adaptive humoral } \\
\text { immunity/Immunostimulant }\end{array}$ & [37] \\
\hline $\begin{array}{l}\text { Tinospora cordifolia } \\
\text { (Thunb.) Miers }\end{array}$ & Arabinogalactan & $\begin{array}{c}\text { Activation of adaptive } \\
\text { immunity/Immunostimulant }\end{array}$ & [38] \\
\hline $\begin{array}{l}\text { Withania somnifera }(\mathrm{L} .) \\
\text { Dunal }\end{array}$ & $\begin{array}{l}\text { Steroidal lactones } \\
\text { (withaferin A) }\end{array}$ & $\begin{array}{c}\text { Adaptogen effects, stimulation of adaptive } \\
\text { humoral and cellular } \\
\text { immunity/Immunostimulant }\end{array}$ & {$[39,40]$} \\
\hline $\begin{array}{l}\text { Zingiber officianalis } \\
\text { Roscoe }\end{array}$ & Phenolics (gingerols) & $\begin{array}{l}\text { Activation of adaptive humoral } \\
\text { immunity/Immunostimulant }\end{array}$ & [41] \\
\hline
\end{tabular}


The best known immunostimulant species is echinacea (Echinacea purpurea (L.) Moench, E. pallida Nutt. and E. angustifolia DC), characterized by immunostimulant properties on both innate and adaptive response, associated with antiviral, antinflammatory and antimicrobial effects [42]. More recently, its ability to indirectly boost the immune system, through the modulation of gut microbiome, has been highlighted [18]. All the phytocomplex seems to be involved in these properties, however, alkylamides and purified polysaccharides have been found to induce immunomodulatory effects [42,43]. The immune boosting properties of echinacea, particularly as enhancers of macrophage and lymphocyte activation, have also been highlighted in clinical studies; however, further high-quality studies are required for better characterizing the possible usefulness of echinacea byproducts as immunomodulators [44].

Several preclinical and clinical evidence also highlighted the ability of Curcuma longa L. to activate cellular immunity and to interfere with inflammation, thus acting as an immune booster [42].

Furthermore, some adaptogenic plants, such as Panax ginseng C.A. Meyer, Astragalus membranaceous (Fisch.) Bge., and Withania somnifera (L.) Dunal can indirectly stimulate the immune system, through improving the resistance to stress $[35,45]$. Indeed, ginseng has been reported able to prevent several diseases through modulating the immune system and gut microbiome, thus suggesting its usefulness as an immunity boosting dietary supplement [36]. Similarly, the immunomodulatory properties of W. somnifera and its constituent withaferin A have been reported [39]. At last, preliminary studies have highlighted the immunomodulatory effects of other medicinal plants, such as Asparagus racemosus Willd., Azadirachta indica A. Juss., Artocarpus tonkinensis A. Chev. Ex Gagnep, Syzigium aromaticum (L.) Merr. and L.M. Perry and Hypoxis rooperi T. Moore [26,33,37,46,47].

Details about the bioactive constituents and the mechanisms of actions of medicinal plants known to modulate the immune function are reported in Table 1.

Several phytochemicals, especially alkaloids, phenolics, glycoproteins and saponins (Figure 2), have been reported to possess antinflammatory and immune modulating properties [48]. Moreover, terpenoids, polysaccharides and fatty acids (Figure 2) have received considerable attention as possible immunomodulatory agents for further application in immune disorders [48,49].

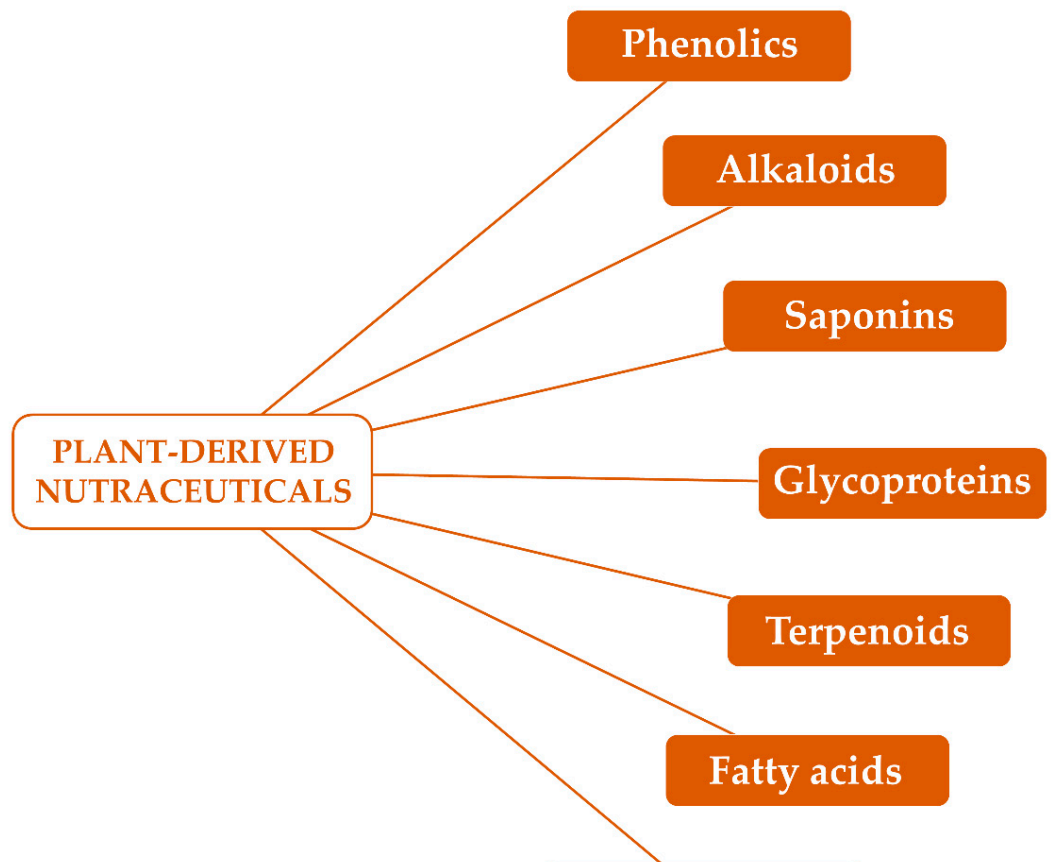

Polysaccharides

Figure 2. Major groups of plant-derived nutraceuticals able to modulate the immune function. 
Particularly, aristolochic acid, an alkaloid from Aristolochia clematitis L., showed immunostimulatory properties, by enhancing the phagocytic activity of peritoneal macrophages and leukocytes; however, its potential cannot be exploited, because of its carcinogenic risk [50]. Likewise, vincristine and staurosporine act as immunostimulants at low doses, while as immunosuppressors at higher doses [51]. Among polyphenols, resveratrol stimulated both cellular and humoral immunity in preclinical models, thus preventing pathogen replication and inflammation, and promoted antitumor immune response too [52]. Furthermore, cichoric acid from echinacea promoted phagocytic activity, both in vitro and in vivo [53]. Anti-inflammatory and immune-modulatory effects has been highlighted for curcumin too, although the poor bioavailability limits its clinical application [54].

In the present review, up to date knowledge on the scientific basis for the immunomodulatory activity and clinical relevance of some emerging classes of plant-derived nutraceuticals, including polysaccharides, fatty acids and labdane diterpenes, has been reported. A comprehensive search was made using PubMed and SCOPUS electronic databases and selecting English as the preferred language, although no language limitations nor filters were applied. For more specific requirements, Google Scholar and ClinicalTrials.gov were considered too. The following searching keywords and their combinations through the Boolean logical operators were used: "herbal immunomodulators", "phytochemicals", "immune system", "nutraceuticals", "medicinal plants", "immunomodulation", "immune system boosters", "immunosuppressors", "immunoadjuvants", "gut microbiome", "natural occurrence", "chemical features", "preclinical studies", "clinical trials", "polysaccharides", "echinacea", "astragalus", "ß-glucan", "fatty acids", "PUFA", "oleic acid", "punicic acid", " $\gamma$-linolenic acid", "linoleic acid", "evening primrose oil", "borage oil", "flaxseed oils", "labdane diterpenes" and "andrographolide".

This overview allows one to identify novel immune system modulators to be usefully exploited for health promoting and disease preventing purposes.

\section{Polysaccharides}

\subsection{Chemical Features}

Polysaccharides are carbohydrate macromolecules containing at least 10 monosaccharide units, joined by glycosidic linkages to form long-chain molecules, which can be both linear and highly branched. They are called homopolysaccharides when constituted of the same monosaccharide unit, while heteropolysaccharides if different units are present. Some of them are also referred to as dietary fibres, meaning that these macromolecules are neither digested nor absorbed in the human small intestine [55].

Several polysaccharides have been found to modulate both innate and adaptive immune responses, among which, glucans, mannans, pectins, fucoidans, galactans, fructans, and xylans are the most studied (Figure 3) [56].

Chemical structure, molecular weight, conformation, the presence of functional groups (i.e., acetyl and sulfate groups), and branching have been identified as structural features for the immunostimulatory properties of polysaccharides. The chemical structures of the polysaccharides associated with immunomodulatory properties are displayed in Figure 4.

Glucans are based on the D-glucopyranosyl unit (homoglucans); the different glycosidic bonds, namely $(\beta 1 \rightarrow 4),(\beta 1 \rightarrow 3)$, and $(\beta 1 \rightarrow 6)$ or $(\alpha 1 \rightarrow 3),(\alpha 1 \rightarrow 4)$, and $(\alpha 1 \rightarrow 6)$, allow the production of linear and branched glucans. It seems that $(\beta 1 \rightarrow 3)$-D-glucan moiety, triple helix conformations, sulfation and carboxymethylation of $(\beta 1 \rightarrow 3)$-D-glucans, and chain acetylation are involved in glucan immunostimulatory activity. Regarding $(\alpha 1 \rightarrow 6)(\alpha 1 \rightarrow 4)$-D-glucans, their structure activity relationship is less characterized [56]. 


\section{POLYSACCHARIDES}

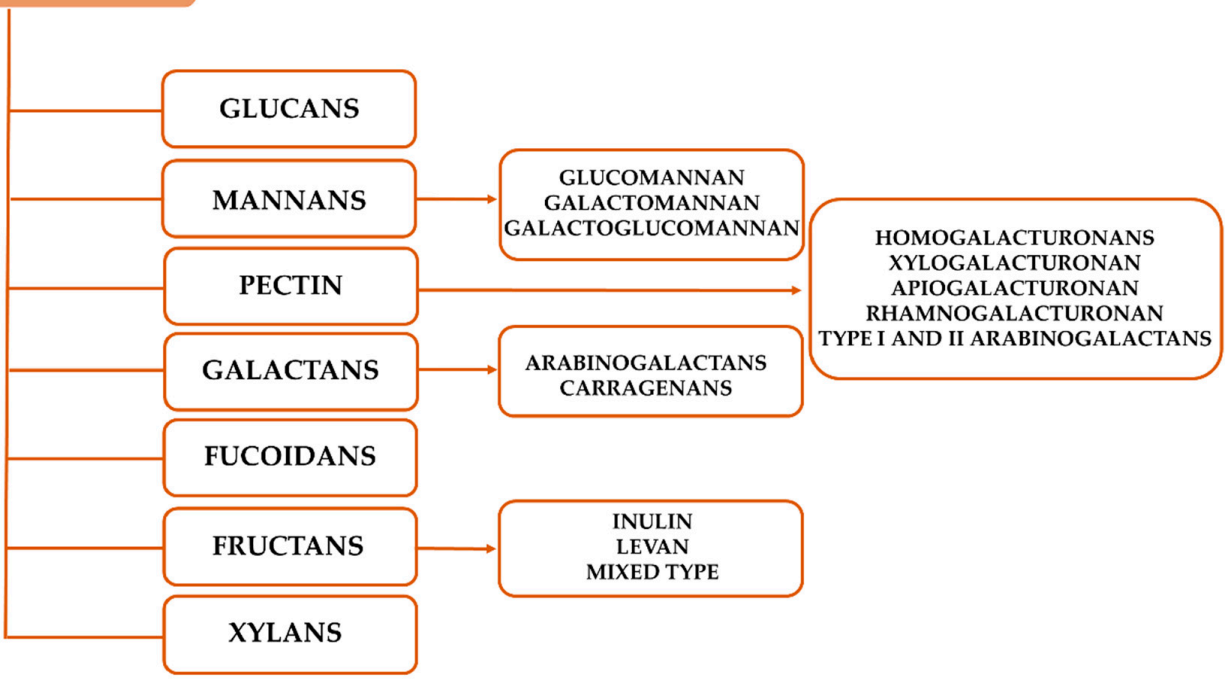

Figure 3. Schematic representantions of the different classes of polysaccharides associated with immune system modulation.
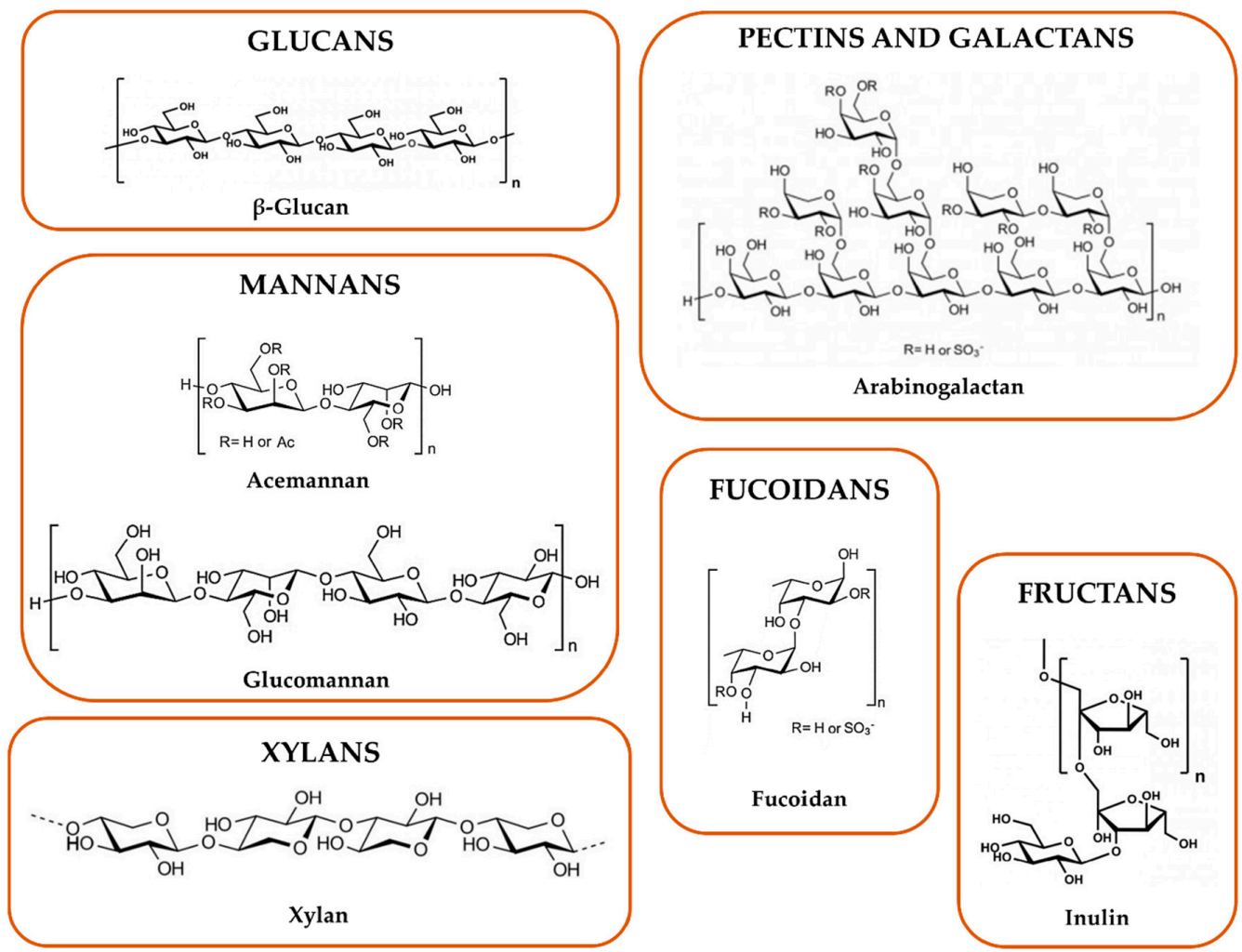

Figure 4. Chemical structure examples of the different classes of polysaccharides.

Mannans consist of a D-mannose backbone, linked mainly by $\beta 1 \rightarrow 4$ bonds, which can be ramified with other monosaccharide, so originating glucomannan, galactomannan, and galactoglucomannan [57]. Furthermore, $(\beta 1 \rightarrow 3)$ - or $(\alpha 1 \rightarrow 3)-$, $(\beta 1 \rightarrow 2)-$, and $(\beta 1 \rightarrow 6)$ - or $(\alpha 1 \rightarrow 6)$-D-mannosidic bonds are reported [56]. The $(\beta 1 \rightarrow 6)$-D-mannan moiety (e.g., galctoglucomannans), acetyl and sulfate group presence, and this kind of branching seems to confer a high immunostimulatory activity [58-60].

Pectins are complex polysaccharides which contain a common galactopyranosyluronic acid. Homogalacturonans, xylogalacturonan, apiogalacturonan, rhamnogalacturonan, type I 
and II arabinogalactans belong to this class. Particularly, type I arabinogalactans (AG-I) possess an $\alpha$-1-arabinofuranosyl and $\beta$-D-galactopyranosyl units linked via position 3 at the main chain, while type II arabinogalactans (AG-II) comprise highly branched polysaccharides with ramified chains of $(\beta 1 \rightarrow 3)$ - and $(\beta 1 \rightarrow 6)$-D-galactopyranosyl units $[61,62]$, to which the arabinosyl units might be attached. The degree of branching, methyl esterification, acetylation, and the type of branched chains and molecular weight determine the structural diversity [63]. Moreover, flexible chain conformation and branched regions are the main ones responsible for the immunomodulatory properties [64,65].

Galactans are polysaccharides rich in galactose and include, beside type I and II arabinogalactans, carrageenans, chemically characterized by repeating disaccharide units of sulfated or unsulfated D-galactose, that are linked by $(\beta 1 \rightarrow 4)$ - and $(\alpha 1 \rightarrow 3)$-bonds. Low molecular weight $(<20 \mathrm{kDa})$ and a high degree of sulfation have been reported as features that high influence their immunomodulatory properties [66,67].

Fucoidans are heteropolysaccharides rich in L-fucopyranosyl sulfated units linked by $(\alpha 1 \rightarrow 2)$, $(\alpha 1 \rightarrow 3)$ or $(\alpha 1 \rightarrow 4)$ bonds. Other monosaccharides can be present, such as galactopyranosyl, mannopyranosyl, xylosepyranosyl and uronic acids [68]. The naturally higher content of sulfate groups and the presence of acetyl groups are associated with a higher stimulatory activity [56].

Fructans are polysaccharides which constitute up to 70 fructose units with a sucrolose terminal molecule. They are classified in inulin with a $(\beta 2 \rightarrow 1)$-D-fructofuranosyl, levan with a $(\beta 2 \rightarrow 6)$-D- fructofuranosyl, and mixed type, with both $(\beta 2 \rightarrow 1)$ - and $(\beta 2 \rightarrow 6)$-linked d-fructofuranosyl moieties. A helical conformation has been associated with the modulatory activity on the immune system $[69,70]$. At last, xylans are polysaccharides containing predominantly a backbone of $(\beta 1 \rightarrow 4)-D-$ xylosepyranosyl units. Other monomers attached to their backbone include $\alpha$-D-glucopyranosyl A units (glucuronoxylans) and $\alpha$-L-arabinofuranosyl units (arabinoxylans). A correlation between their structure and activity has not been elucidated yet [71,72].

\subsection{Natural Occurrence}

Polysaccharides are naturally occuring in animal body fluids, cell walls, bacteria, yeast and fungi, extra cellular fluids, and in plant seeds, stems and leaves, which represent the focus of the present review. The main advantage of plant polysaccharides seems to be the low toxicity with respect to immunomodulatory bacterial polysaccharides and synthetic compounds [73]. Thus, they represent an ideal alternative for immune modulation. A variety of polysaccharides with immunomodulatory properties have been discovered in different species of plants (Table 2). Among the most studied, there are type I and II arabinogalactans from Astragalus membranaceus (Fisch.) Bge., fructans from Allium sativum L. [56], fucogalactoxyloglucan and type II acidic arabinogalactan from Echinacea purpurea L. (Moench), ginsan and panaxanes from Panax ginseng C.A. Meyer, acemannan and aloeride from Aloe vera L. [74], and glucomannan from Amorphallus konjac Koch [75]. 
Table 2. Examples of medicinal plants containing polysaccharides with immune system modulation activities.

\begin{tabular}{|c|c|c|c|}
\hline Plants & Family & $\begin{array}{c}\text { Plant Part of Biological } \\
\text { Interest }\end{array}$ & References \\
\hline Aconitum carmichaeli Debx. & Ranunculaceae & Roots & [76] \\
\hline Allium sativum L. & Liliaceae & Bulb & [77] \\
\hline Aloe vera $\mathrm{L}$. & Liliaceae & Leaves & [78] \\
\hline Amorphallus konjac Koch & Araceae & Tubers & [79] \\
\hline Anadenanthera colubrina (Vell.) Brenan & Fabaceae & Gum & [80] \\
\hline Astragalus membranaceus (Fisch.) Bge. & Fabacee & Root & [64] \\
\hline Carum carvi $\mathrm{L}$. & Apiaceae & Seeds & [81] \\
\hline Centella asiatica L. Urb. & Apiaceae & Aerial parts & [82] \\
\hline Coffea arabica L. and C. robusta L. & Rubiaceae & Beans & [83] \\
\hline Cyamopsis tetragonolobus L. & Fabaceae & Seeds & [84] \\
\hline Dendrobium huoshanense C.Z. Tang et S.J. Cheng & Orchidaceae & Stems & [85] \\
\hline Echinacea purpurea L. (Moench) & Asteracee & Aerial parts & {$[86,87]$} \\
\hline Euterpe oleracea Mart. & Arecaceae & Fruits & {$[88,89]$} \\
\hline Hordeum vulgare var. Tyra & Poaceae & Stems & {$[90]$} \\
\hline Ipomoea batatas L. & Convolvulaceae & Roots & [91] \\
\hline Juniperus scopolorum Sarg. & Cupressaceae & Cones & [92] \\
\hline Lycium barbarian $\mathrm{L}$. & Solanaceae & Fruit & [93] \\
\hline Panax ginseng C.A. Meyer & Araliaceae & Roots & [94] \\
\hline Picea abies L. & Pinaceae & Softwoods & [95] \\
\hline Prunus dulcis (Miller) D. A. Webb. & Rosacee & Seeds & [96] \\
\hline Sophora alopecuroides L. & Fabaceae & Seeds & [97] \\
\hline Tanacetum vulgare $\mathrm{L}$. & Asteraceae & Florets & [98] \\
\hline Tinospora cordifolia (Thunb.) Miers & Menispermaceae & Aerial parts & [99] \\
\hline Trigonella foenum-graecum L. & Fabaceae & Seeds & [100] \\
\hline
\end{tabular}

\subsection{Pharmacological Properties: Preclinical Evidence}

Several studies have shown that polysaccharides from plants can modulate both innate and acquired intestinal immunity, by direct and indirect mechanisms. The former include the activation of immune cells (e.g., macrophages, dendritic cells, natural killer cells, T cells, B lymphocytes), while the latter the short-chain fatty acid (SCFA) formation (Figure 5).

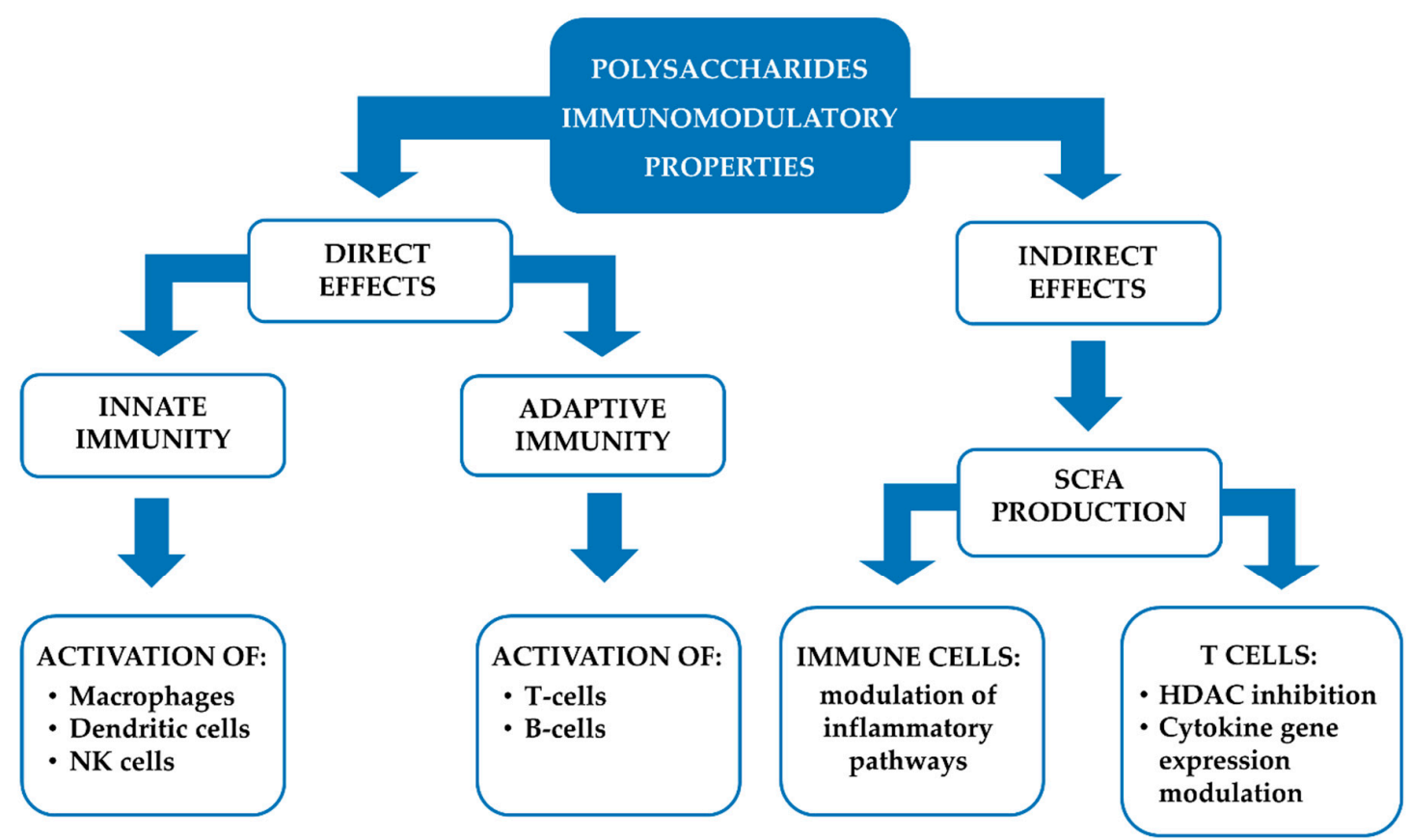

Figure 5. Schematic representantions of the direct and inderect effects of polysaccharides on the immune system. SCFA, short-chain fatty acids; NK, natural killer; HDAC, histone deacetylases. 
The immunomodulatory effects of plant polysaccharides on macrophages are mainly achieved through the generation of reactive oxygen and nitrogen species (ROS and NOS), and the stimulation of cytokines secretion, cell proliferation, and macrophage phagocytic activity [101]. For example, A. membranaceus polysaccharides have been shown to promote nitric oxide (NO) synthesis in macrophages, by inducing the gene expression of inducible nitric oxide synthase (iNOS), through the activation of nuclear factor kappa-B (NF-kB)/Rel [102,103]. Moreover, they were also able to increase the macrophage phagocytic activity, by enhancing their secretion of release factor and intracellular $\mathrm{Ca}^{2+}$ concentration [104,105].

Pectic polysaccharides from Citrus unshiu Marc. have been shown to simultaneously regulate the expression of pro- and anti-inflammatory cytokines. Particularly, they increased the production of the pro-inflammatory cytokines tumor necrosis factor (TNF)- $\alpha$ and interleukin (IL)- 6 and the anti-inflammatory cytokine IL-12 in macrophage RAW264.7, so showing a regulatory mechanism to maintain an equilibrium state [106]. Arabinogalactan from E. purpurea has been reported to increase macrophages activation and IL-1, TNF- $\alpha$ and interferon (IFN)- $\beta$ production [86]. The activation of macrophages by plant polysaccharides seems to be due to specific receptors present on their surface, which initiates the immune response, and exerts an immunomodulatory effect. These receptors are called pattern recognition molecules, and include: Toll-like receptor 4 (TLR4), CD14, complement receptor 3 (CR3), scavenger receptor (SR), mannose receptor (MR), and Dectin-1. Their activation determines a series of intracellular signaling cascades, leading to the transcriptional activation and production of inflammation-related cytokines [101].

Immunity modulation by plant polysaccharides can be achieved also by modulating the cytokine release from intestinal dendritic cells. Indeed, pectin has been shown to reduce IL-6 and IL-10 release induced by the synthetic lipopeptide P3CSK4 [107]. Moreover, inulin, pectin, arabinoxylan and $\beta$-glucan have been found to elevate IL-10/IL-12 ratio and to reduce the release of IFN- $\gamma$, IL-12, IL-1, IL-6, IL-8, monocyte chemoattractant protein (MCP)-1, macrophage inflammatory proteins (MIP)-1 $\alpha$, RANTES and TNF- $\alpha$ by dendritic cells [108]. Polysaccharide enriched extracts of E. purpurea have been found to promote the phenotypic and functional maturation of dendritic cells by modulating c-Jun N-terminal kinase (JNK), p38 mitogen-activated protein kinase (MAPK) and NF- $\kappa$ B pathways [109].

The activation of natural killer (NK) cells also contributes to the immunity modulation by polysaccharides. Indeed, it has been shown that $A$. membranaceus polysaccharides can enhance the activity and killing effects of NK cells and promote their proliferation in rats with gastric cancer [110]. Moreover, they were able to increase CD3-CD4-CD8+ NKs in peripheral blood lymphocytes [111]. NKs activation is probably due to the polysaccharides interaction with the killer cell lectin-like receptor K1(KLRK1) of NKs [112]. Arabinoxylans extracted from wheat bran have been shown to inhibit the growth of transplantable tumors, and to promote the NK cell activity in S180 tumor-bearing mice [113]. Moreover, the MGN-3 rice bran arabinoxylan showed to enhance natural killer (NK) cell activity in aged C57BL/6 and C3H mice upon its intraperitoneal injection [114].

Adaptive immunity is also modulated by plant polysaccharides. Particularly, Fan et al. have shown that polysaccharides from A. membranaceus significantly up-regulated the proliferation of B lymphocytes, probably through the interaction with immunoglobulin on the surface of B cells [115-117]. A. membranaceus polysaccharides were also able to increase the number of CD3+CD4+CD8+ memory $\mathrm{T}$ helper (Th) cells and CD3+CD4-CD8+ cytotoxic T cells [111]. Moreover, they also enhance the CD4+/CD8+ T cell ratio [118]. Furthermore, arabinoxylan were found to increase the activation of Tand B-cells and humoral and cell-mediated immunity in tumor bearing mice [71].

At last, $\beta$-glucan microparticles enhanced T-cell activation and proliferation in vitro [119]. Their ability to affect the immune system by inducing Th1 and/or Th2 type immune response makes polysaccharides suitable adjuvants of the vaccine. Among them, inulin, chitosan, glucans and mannans have been most extensively studied. Particularly, the gamma and delta forms of inulin fructan have shown adjuvant activity against infectious pathogens by stimulating both Th1 and Th2 responses without inducing immunoglobulin E (IgE) production [120]. Moreover, Advax, 
a polysaccharide derived from delta inulin, has demonstrated to increase the immunization derived from influenza vaccine in mice. Particularly, an induction of neutralizing antibody and memory B-cell against influenza, an increase in CD4 and CD8 T-cell proliferation, and enhanced levels of IL-2, IFN- $\gamma$, IL-5, IL-6 were highlighted [121].

Advax also enhanced the immunogenicity of hepatitis B surface antigen (HBs) in mice and guinea pigs, by increasing both anti-HBs antibody titers and anti-HBs CD4 and CD8 T-cells. Th1, Th2 and Th17 responses were increased too [122]. Astragalus polysaccharides were also used as adjuvants of Hepatitis B virus DNA vaccine in a mice model, showing increased HBsAg-specific antibody levels, higher activity of T cells, the production of IL- 4 , IL- 2 and IFN- $\gamma$ by CD4+ T cells, and IFN- $\gamma$ expression of CD8+ T cells. Moreover, a stimulation of cytotoxic lymphocytes and dendritic cells maturation, and a reduction in the frequency of regulatory T cells were observed [123]. Mannans and fructooligosaccharide have also been shown to possess adjuvanticity [124,125].

Furthermore, indirect effects are involved in the immunomodulatory properties of polysaccharides. In particular, dietary fibers (e.g., inulin, mannan, $\beta$-glucan, pectin) are metabolized by intestinal bacteria in the anaerobic environment of the cecum and colon, so generating SCFA, such as acetate, propionate and butyrate [126]. These molecules are able to cross the gut epithelium and interact with surface receptors on the immune cells, such as the G-protein coupled receptors (GPRs) 41 and 43 [127]. The activation of GPRs by SCFA modulates inflammatory signalling pathways, such as NF- $\mathrm{kB}, \mathrm{ERK}$ and p38 MAPK [128,129].

Moreover, it has been highlighted that SCFA can reach T lymphocyte nucleus, so modulating several functions through a histone deacetylase (HDAC) inhibition. Recently, SCFA have been reported able to induce $\mathrm{T}$ cells metabolic alterations by enhancing the mTOR complex activity. Particularly, after absorption into T cells, SCFA can stimulate the activity of mTOR complex, so increasing the conversion of pyruvate into acetyl-CoA. Moreover, the acetyl groups from SCFA can be link to CoA and enter the tricarboxylic acid cycle. The increased levels of citrate are exported from mitochondria into the cytoplasm, where the enzyme ATP citrate lyase converts it into acetyl-CoA, then used by histone acetyltransferases (HATs) for histone acetylation and the regulation of cytokine gene expression [126].

\subsection{Clinical Studies}

Some clinical studies have been carried out on the potential immunomodulatory properties of polysaccharides, and A. membranaceus, E. purpurea and $\beta$-glucan have been most investigated.

In a clinical trial on $A$. membranaceus by Jiang et al. [130], twenthy-eight stable continuous ambulatory peritoneal dialysis patients were treated with peritoneal dialysis fluid containing astragalus $(20 \mathrm{~mL} / 2 \mathrm{~L})$ for one week. An increase in the macrophage phagocytic capacity, NO and TNF- $\alpha$ contents were observed in patients compared to those before the treatment [130]. Furthermore, Ji et al. [131] investigated the effect of astragalus pre-operative treatment of colorectal cancer patients $(n=128)$ on immune function. Results showed that astragalus pre-operative treatment promoted the NK cell activity in postoperative patients. In addition, the possible immunomodulatory activity of astragalus in patients with acute exacerbations of bronchial asthma $(n=72)$ has been investigated [132]. Particularly, it was observed that the combination of conventional therapy with astragalus injection for 14 days improved the effects of routine treatment, by enhancing T lymphocyte and NK-cells immune function.

Results of clinical trials on the immune system modulation by E. purpurea are controversial. Particularly, a randomized blinded trial carried out on 108 patients revealed that there was no significant difference in the incidence and severity of colds and respiratory infection between echinacea treatment (8 weeks) and placebo groups. However, a small decrease of total lymphocyte counts was observed [133].

Another randomized, placebo controlled, double-blind clinical trial investigated the effect of different echinacea preparations, namely Echinaforce ${ }^{\circledR}$ (E. purpurea preparation from $95 \%$ herba and $5 \%$ radix), E. purpurea concentrate (same preparation at 7 times higher concentration), special E. purpurea radix preparation (totally different from that of Echinaforce ${ }^{\circledR}$ ) on the reduction of the complaint index, 
defined by 12 symptoms in healthy, adult volunteers who caught a common cold. The treatment continued until the enrolled patients felt healthy again, but not longer than 7 days. The supplementation with Echinaforce ${ }^{\circledR}$ and its concentrated preparation showed to be significantly more effective than the special echinacea extract or placebo. Moreover, all treatments were well tolerated [134]. Furthermore, prevention trials have been carried out, showing that echinacea products slightly reduce the risk of getting a cold in healthy individuals [135]. However, the heterogeneity (e.g., different species and part used) of preparations used in the trials makes the conclusions on the potential immunomodulatory properties of echinacea difficult.

Clinical trials concerning the $\beta$-glucan immunomodulatory properties have also been carried out, although in some cases, yeast-derived-glucan were used. Particularly, three randomized, double-blind, placebo-controlled studies have evaluated the effects of short-term $\beta$-glucan supplementation on children with chronic respiratory problems. After 30 days' treatment, significant improvements in immunoglobulin, lysozyme, exhaled nitric oxide, and calprotectin production were found [136-138]. Furthermore, the combination of resveratrol plus carboxymethyl- $\beta$-glucan as a solution for aerosol has been tested in clinical trials. Particularly, the ability of the combination to prevent or treat recurrent respiratory infections in children was studied $[139,140]$. In both cases, resveratrol plus carboxymethyl- $\beta$-glucan had a positive impact on children clinical conditions. Indeed, nasal obstruction, rhinorrhea, sneezing, cough, fever, medication use, medical visits, and school absence were significantly reduced. Moreover, resveratrol plus carboxymethyl- $\beta$-glucan have also been shown to relief nasal symptoms in children with allergic rhinitis, due to pollen allergy [141].

At last, mannans should be mentioned. They have been reported to possess adjuvant-vaccine properties in clinical studies, probably mediated by its interaction with mannose receptors. Particularly, it has been shown that oxidized mannan-mucin 1 can be useful as an adjuvant in the breast cancer immunotherapy. Indeed, a 12-15 years follow-up has highlighted that it decreases the cancer recurrence rate and prolongs recurrence time, without inducing toxicity or adverse reactions [124].

\section{Fatty Acids}

\subsection{Chemical Features}

Fatty acids (FA) are a large group of lipids, characterized by a different number of carbons, arranged in a linear carbon chain skeleton of variable length with a terminal carboxylic group [142]. Based on the number of carbons in the chain, fatty acids can be classified as shortchain fatty acids (SCFA; aliphatic tails up to a maximum of six carbons), medium-chain fatty acids (MCFA; aliphatic tails of 7-12 carbons), long-chain fatty acids (LCFA; aliphatic tails of 13 to 21 carbons) and very long-chain fatty acids (VLCFA; aliphatic tails of 22 and more carbons) [143].

Among them, SCFA, such as acetate, propionate, and butyrate, are produced by gut microbiota enzymes (i.e., propionate-CoA transferase and propionaldehyde dehydratase) during the metabolism of carbohydrates and peptides containing branched-chain amino acids [144]. Bacteroidetes are reported to be mainly responsible for the production of acetate and propionate, while Firmicutes are the primary contributors of butyrate; however, other bacteria such as Lactobacillus and Bifidobacterium spp. are involved too [144].

Based on the presence of different double bonds in this structure, fatty acids can be distinguished in saturated fatty acids (SFA), lacking double bonds in their carbon backbone, and unsaturated FA (UFA), which may contain one or more double bonds, thus leading to monounsaturated (MUFA) and polyunsaturated FA (PUFA) [143]. SFA include palmitic acid (C16:0), lauric acid (C12:0), myristic acid (C14:0), and stearic acid (C18:0), whereas n-9 oleic acid (C18:1) is an example of MUFA.

Furthermore, PUFA class includes fatty acids such as $\alpha$-linolenic acid (ALA; C18:3), linoleic acid (LA; C18:2) and further long-chain metabolites [143]. The number of carbon atoms and unsaturated bond position are used for the systematic nomenclature of FA. Moreover, the greek letters omega $(\omega)$ and delta $(\Delta)$ are included, to indicate how far a double bond is from the terminal methyl carbon and the 
presence and position of one or more double or triple bonds in the carbon backbone, respectively [143]. A further " $\omega$ " or " $n$ " classification designates the position of the first double bond in the skeleton from the end opposite to the carboxy group. Accordingly, oleic acid is classified as a $\omega-9$ (or n-9) fatty acid, while linoleic acid and $\alpha$-linolenic acid are $\omega-6$ (or n-6) and $\omega-3$ (or n-3) fatty acids, as they contain the double bond nine, six and three carbons from the methyl end [143]. Nomenclature of the major representative fatty acids in the different FA classes is displayed in Table 3.

Table 3. Nomenclature and chemical features of some representative long-chain fatty acids.

\begin{tabular}{|c|c|c|c|c|}
\hline \multirow[b]{2}{*}{ Fatty Acid } & \multirow{2}{*}{$\begin{array}{c}\text { Class of } \\
\text { Long-Chain Fatty } \\
\text { Acid }\end{array}$} & \multirow[b]{2}{*}{ IUPAC Name } & \multicolumn{2}{|l|}{ Abbreviation } \\
\hline & & & $\begin{array}{c}\text { Delta }(\Delta) \\
\text { Nomenclature }\end{array}$ & $\begin{array}{c}\text { n- or } \\
\omega \text {-Nomenclature }\end{array}$ \\
\hline Palmitic acid & SFA & Hexadecanoic acid & 16:0 & $16: 0$ \\
\hline Stearic acid & SFA & Octadecanoic acid & 18:0 & 18:0 \\
\hline Oleic acid & MUFA & (9E)-Octadec-9-enoic acid & $18: 1 \Delta 9$ & $18: 1 n-9$ or $18: 1 \omega-9$ \\
\hline Punicic acid & Conjugated PUFA & $\begin{array}{l}\text { (9Z,11E,13Z)-9,11,13- } \\
\text { Octadecatrienoic acid }\end{array}$ & $18: 3 \Delta 9,9,11,13$ & $18: 3 n-5$ or $18: 3 \omega-5$ \\
\hline $\begin{array}{c}\alpha \text {-Linolenic acid } \\
\text { (ALA) }\end{array}$ & PUFA & $\begin{array}{c}\text { (9Z,12Z,15Z)-Octadeca- } \\
\text { 9,12,15-trienoic acid }\end{array}$ & $18: 3 \Delta 9,12,15$ & $18: 3 n-3$ or $18: 3 \omega-3$ \\
\hline Stearidonic acid (SA) & PUFA & $\begin{array}{c}\text { (6Z,9Z,12Z,15Z)-Octadeca- } \\
\text { 6,9,12,15-tetraenoic acid }\end{array}$ & $18: 4 \Delta 6,9,12,15$ & $18: 4 n-3$ or $18: 4 \omega-3$ \\
\hline Eicosatetraenoic acid (ETA) & PUFA & $\begin{array}{l}(2 Z, 4 Z, 5 Z, 8 Z)-2,4,6,8- \\
\text { Icosatetraenoic acid }\end{array}$ & $20: 4 \Delta 2,4,6,8$ & $20: 4 n-3$ or $20: 4 \omega-3$ \\
\hline Eicosapentaenoic acid (EPA) & PUFA & $\begin{array}{c}(2 \mathrm{E}, 4 \mathrm{E}, 6 \mathrm{E}, 8 \mathrm{E}, 10 \mathrm{E})-2,4,6,8,10- \\
\text { Icosapentaenoic acid }\end{array}$ & $20: 5 \Delta 2,4,6,8,10$ & $20: 5 n-3$ or $20: 5 \omega-3$ \\
\hline $\begin{array}{c}\text { Docosahexaenoic acid } \\
\text { (DHA) }\end{array}$ & PUFA & $\begin{array}{c}\text { (4Z,7Z,10Z,13Z,16Z,19Z)-Docosa- } \\
\text { 4,7,10,13,16,19-hexaenoic acid }\end{array}$ & $22: 6 \Delta 4,7,10,13,16,19$ & $22: 6 n-3$ or $20: 6 \omega-3$ \\
\hline Linoleic acid (LA) & PUFA & (9Z,12Z)-Octadeca-9,12- dienoic acid & $18: 2 \Delta 9,12$ & $18: 2 n-6$ or $18: 2 \omega-6$ \\
\hline$\gamma$-Linolenic acid (GLA) & PUFA & $\begin{array}{l}(6 \mathrm{Z}, 9 \mathrm{Z}, 12 \mathrm{Z})-\text { Octadeca-6,9,12- } \\
\text { trienoic acid }\end{array}$ & $18: 3 \Delta 6,9,12$ & $18: 3 n-6$ or $18: 3 \omega-6$ \\
\hline $\begin{array}{c}\text { Dihomo } \\
\gamma \text {-Linolenic acid (DGLA) }\end{array}$ & PUFA & $\begin{array}{l}(8 \mathrm{Z}, 11 \mathrm{Z}, 14 \mathrm{Z})-\mathrm{Icosa}-8,11,14- \\
\text { trienoic acid }\end{array}$ & $20: 3 \Delta 8,11,14$ & $20: 3 n-6$ or $20: 3 \omega-6$ \\
\hline $\begin{array}{l}\text { Arachidonic acid } \\
\text { (AA) }\end{array}$ & PUFA & $\begin{array}{l}(5 \mathrm{E}, 8 \mathrm{E}, 11 \mathrm{E}, 14 \mathrm{E})-\text { Icosa-5,8,11,14- } \\
\text { tetraenoic acid }\end{array}$ & $20: 4 \Delta 5,8,11,14$ & $20: 4 n-6$ or $20: 4 \omega-6$ \\
\hline $\begin{array}{l}\text { Docosapentaenoic acid } \\
\text { (DPA) }\end{array}$ & PUFA & $\begin{array}{c}(7 Z, 10 Z, 13 Z, 16 Z, 19 Z)- \\
\text { Docosa-7,10,13,16,19- pentaenoic acid }\end{array}$ & $22: 5 \Delta 7,10,13,16,19$ & $22: 5 n-6$ or $22: 5 \omega-6$ \\
\hline
\end{tabular}

Unsaturated fatty acids can be characterized on the basis of the cis- or trans- orientation of the double bonds. Usually, natural fatty acids carry a cis- configuration, although some trans-fatty acids can also occur in foods as a consequence of the hydrogenation process, which can move double bonds from their naturally occurring position to a trans-configuration [143]. Trans-fatty acids are considered undesirable compounds in foods, as their intake is associated with an increased risk of cardiovascular and metabolic diseases [145].

PUFA can be further classified depending on the relative positions of the double bonds, as conjugated (double-bonded carbon atoms alternate with single bonds) and unconjugated (double bonds separated by one or more single bonds) [143]. Unconjugated PUFA, especially $\omega-3, \omega-6$, and $\omega-9$ series, are the most occurring in nature. The most common conjugated PUFA are trienes, such as octadecatrienoic acids (e.g., punic acid, calendic acid).

Fatty acids within the series are biosynthetically related, being synthesized through enzymatic processes of desaturation, chain elongation, and chain shortening [146]. Particularly, the biosynthesis of $\omega-3$ and $\omega-6$ PUFA starts from $\alpha$-linolenic acid (ALA or linolenate; 9,12,15-18:2) and linoleic acid (LA or linoleate; 9,12-18:2), respectively (Figure 6).

These precursors cannot be synthetized by mammals, which lack the $\Delta 12$ and $\Delta 15$ desaturases responsible for the convertion of 18:1 $\omega-9$ FA to 18:2 $\omega-6$ and 18:3 $\omega-3$ PUFA, and must be supplied by the diet, thus being considered as essential fatty acids. 
The initial rate-limiting step for the biosynthesis of $\omega 3$ and $\omega 6$ fatty acids is the insertion of a further double bond at the $\Delta 6$ carbon into the carbon chain of ALA and LA, through the help of a $\Delta 6$ desaturase enzyme: stearidonic acid (SA; 6,9,12,15-18:4) and $\gamma$-linolenic acid (GLA; 6,9,12-18:3) are formed, respectively. These compounds are converted to eicosatetraenoic acid (ETA; 2,4,6,8-20:4) and dihomo $\gamma$-linolenic acid (DGLA; 8,11,14-20:3) by the elongase 5, being further converted to eicosapentaenoic acid (EPA; 2,4,6,8,10-20:5) and arachidonic acid (AA; 5,8,11,14-20:4), by the addition of a double bond at the $\Delta 5$ position, through a $\Delta 5$ desaturase. Further elongations convert EPA and AA to docosapentaenoic acid $(2,4,6,8,10-22: 5)$ and adrenic acid $(7,10,13,16-22: 4)$; then, a desaturation by $\Delta 6$ desaturase generates docosahexaenoic acid (DHA; 4,7,10,13,16,19-22:6) [146]. Both series of fatty acids can be further metabolized by cyclooxygenase and lipoxygenase enzymes, to obtain eicosanoids, including prostaglandins, thromboxanes and leukotrienes, acting as central modulators of the inflammatory process [146].

The byosynthetic pathways of $\omega 3$ and $\omega 6$ fatty acids are interconnected; indeed, it is known that long-chain derivatives from linolenic acid are accumulated in tissue only slightly when competing $\omega 6$ analogues exceed their amounts. Therefore, suitable levels can be reasonably obtained through diet and when an optimum ratio of $\omega 3$ and $\omega 6$ series is maintained.

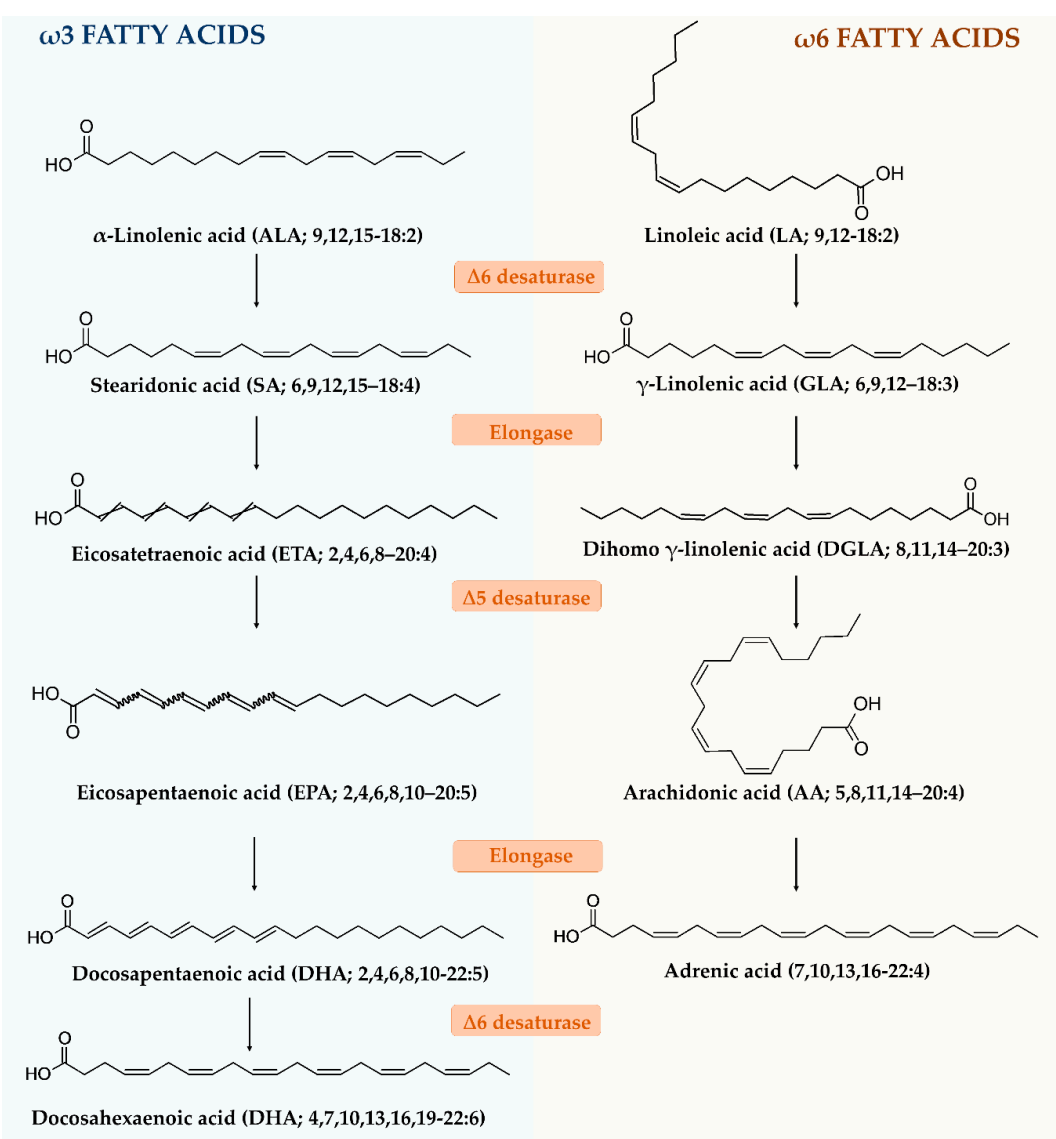

Figure 6. Biosynthetic pathways of $\omega-3$ and $\omega-6$ fatty acids.

\subsection{Natural Occurrence}

Fatty acids occur widely in nature, being identified in both animal tissue and plants. Particularly, short-chain saturated acids are components of milk fats: in bovine milk, butanoic acid along with other SCFA and MCFA have been reported [147]. Likewise, the MCFA lauric acid and myristic acid are the major components of the oils obtained from some Lauraceae and Myristiceae species [148]. Moreover, palmitic acid is the most representative SFA in vegetable oils, such as palm oil [149]. 
Fatty acids with immune modulating properties mainly belong to the long-chain classes; among them, punicic acid is a peculiar conjugated triene, found to be a unique component of pomegranate seed oil [150], while oleic acid is one of the most widely distributed fatty acids: it represents $49 \%$ to $83 \%$ of total FA in olive oil, although it does occur in high amounts in other oils, such as those from grape seeds, canola and sufflower [151,152].

Moreover, $\omega 3$ and $\omega 6$ fatty acids have been highlighted in several natural sources, wherein both series co-occur (Table 4), although in different amounts [153].

Table 4. Major natural sources of long-chain monounsaturated (MUFA) and polyunsaturated fatty acids (PUFA) associated with immune system modulating activities and relative amounts.

\begin{tabular}{|c|c|c|c|}
\hline & Species (Byproduct) & Amount (\%) & References \\
\hline \multicolumn{4}{|l|}{ MUFA } \\
\hline \multirow[t]{3}{*}{ Oleic acid } & $\begin{array}{l}\text { Olea europea L. } \\
\text { (fruit oil) }\end{array}$ & $56-84 \%{ }^{a}$ & [151] \\
\hline & $\begin{array}{l}\text { Vitis vinifera } \mathrm{L} . \\
\text { (grapeseed oil) }\end{array}$ & $9-17 \%$ & [154] \\
\hline & $\begin{array}{l}\text { Brassica spp. } \\
\text { (rapeseed oil) }\end{array}$ & $60-80 \%$ & [155] \\
\hline \multicolumn{4}{|l|}{ Conjugated PUFA } \\
\hline \multirow[t]{2}{*}{ Punicic acid } & $\begin{array}{c}\text { Punica granatum } \mathrm{L} . \\
\text { (pomegranate seed oil) }\end{array}$ & $70-85 \%$ & [150] \\
\hline & $\begin{array}{l}\text { Momordica charantia } \mathrm{L} . \\
\text { (bitter gourds seed oils) }\end{array}$ & $1.5-16 \%$ & [156] \\
\hline \multicolumn{4}{|l|}{ Essential $\omega 3-P U F A$} \\
\hline \multirow[t]{3}{*}{$\alpha$-Linolenic acid (ALA) } & $\begin{array}{l}\text { Linum usitatissimum L. } \\
\text { (flaxseed oil) }\end{array}$ & $55-57 \%$ & {$[153,157]$} \\
\hline & $\begin{array}{l}\text { Salvia hispanica L. } \\
\text { (chia seeds) }\end{array}$ & $17.8 \%$ & [153] \\
\hline & $\begin{array}{l}\text { Perilla frutescens var. frutescens L. } \\
\text { (seeds) }\end{array}$ & $54-64 \%$ & [158] \\
\hline EPA, DHA & Fish oils & $4-13 \%$ & [153] \\
\hline \multicolumn{4}{|l|}{ Essential $\omega 6$-PUFA } \\
\hline \multirow[t]{7}{*}{ Linoleic acid (LA) } & Borago sp. (seed oil) & $26.8-37.9 \%$ & [159] \\
\hline & $\begin{array}{l}\text { Oenothera biennis L. } \\
\text { (seed oil) }\end{array}$ & $70-74 \%$ & [160] \\
\hline & $\begin{array}{l}\text { Cannabis sativa } \mathrm{L} . \\
\text { (hamp seed oil) }\end{array}$ & $27-58 \%$ & {$[153,161]$} \\
\hline & $\begin{array}{l}\text { Glycine max }(\mathrm{L} .) \text { Merr. } \\
\text { (soybean) }\end{array}$ & $50.4 \%$ & {$[153,161]$} \\
\hline & $\begin{array}{l}\text { Bertholletia excelsa } \\
\text { (Dried brazilnuts) }\end{array}$ & $23.8 \%$ & {$[153,161]$} \\
\hline & $\begin{array}{l}\text { Juglans regia } \mathrm{L} . \\
\text { (dried walnuts) }\end{array}$ & $33.8 \%$ & {$[153,161]$} \\
\hline & $\begin{array}{l}\text { Zea mays L. } \\
\quad(\text { corn })\end{array}$ & $53.2 \%$ & {$[153,161]$} \\
\hline \multirow[t]{6}{*}{$\gamma$-Linolenic acid (GLA) } & Borago sp. (seed oil) & $9.6-39.8 \%$ & [159] \\
\hline & $\begin{array}{l}\text { Oenothera biennis L. } \\
\text { (seed oil) }\end{array}$ & $8-10 \%$ & [160] \\
\hline & Ribes nigrum & $15-19 \%{ }^{\text {a }}$ & [162] \\
\hline & (seed oil) & & \\
\hline & $\begin{array}{l}\text { Echium spp. } \\
\text { (seed oil) }\end{array}$ & $31.2-47.1 \%$ & [159] \\
\hline & $\begin{array}{l}\text { Ranunculus spp. } \\
\quad \text { (seed oil) }\end{array}$ & $37.9-39.7 \%$ & [159] \\
\hline
\end{tabular}

a referred to the total amount of fatty acids. 
Some vegetable oils, including rapseed, hemp seed, and sunflower oils, contain higher levels of LA (essential $\omega 6$ PUFA), while ALA (essential w3 PUFA) is in lower proportion; a similar trend has also been reported for soybean, corn, and for dried black walnuts and brazilnuts; conversely, higher amounts of ALA respect to LA are reported in flaxseed oil and in the seeds of chia and perilla [153]. Likewise, green leafy vegetables seem to be an interesting source of ALA [163]. Fish oils are also sources of both EPA and DHA ( $\omega 3$ PUFA), with lower amounts of DPA ( $\omega 6$ PUFA) [153].

Wild marine species showed to contain higher $\omega 3$ PUFA levels compared to farmed ones, likely due to the feed composition [153]. Some vegetables can supply both the essential PUFA and some derivative fatty acids. Particularly, the oils obtained from the seeds of Borago spp., Echium spp., Ranunculus spp. and Oenothera biennis L. have been reported to contain high levels of both LA and $\gamma$-linolenic acid (GLA) $[159,160]$.

\subsection{Pharmacological Properties: Preclinical Evidence}

Fatty acids play energetic, metabolic, and structural functions, being the main component of phospholipids, triglycerides, diglycerides and monoglycerides. A separate category is represented by SCFA, which act as metabolites of carbohydrates, produced by gut microbiota: their role in the modulation of immune function is described in Section 2.3.

Long-chain fatty acids have been found involved in immune modulation, being able to affect both innate and adaptive response. Although specific profiles characterize each class of fatty acids, these effects are mainly ascribed to their ability to target the cell membrane, where they can be incorporated, thus changing membrane composition and fluidity and modulating membrane-protein interaction and signal transduction. Furthermore, a role in the control of inflammation has been reported. Epithelial growth factor receptors (a critical crossroad of multiple receptor pathways which is potentially implicated in the regulation of proliferation and possibly involved in atherogenesis) are considered possible targets for unsaturated fatty acids [164].

MUFA, especially oleic acid, have attracted great attention in the years as possible immunomodulating nutrients. Preclinical studies demonstrated the ability of oleic acid to modulate the immune system, through affecting both innate and adaptive immunity response [164]. Indeed, it diminished NK cell activity [165] and the expression of the leucocyte adhesion molecules, which have shown to be implicated in some pathophysiological conditions, such as rheumatoid arthritis [165]. Furthermore, it enhanced neutrophil aggregation and neutrophil-endothelial cell attachment, phagocytic and candidacidal capacities [166,167].

In regard to adaptive response, it inhibited the proliferation of immune cells, such as Jurkat $\mathrm{T}$ cells and lymphocytes, likely through the regulation of the cell cycle, although the true mechanisms remain to be clarified [164]. Similar suppressive effects were also highlighted for its synthetic analogue minerval and confirmed in animal models $[164,168]$. Furthermore, the treatment with oleic acid and minerval induced proapoptotic effects in Jurkat (T lymphocyte) and Raji (B lymphocyte) cells, likely due to mitochondrial depolarization and ROS production [168-170].

Recently, oleate has been reported to be able to protect macrophages from palmitate-induced lipotoxicity; moreover, it has been associated with an increase in the regulatory phenotype of the myeloid MSC-2 suppressor cells and suppression of activated T cells [171,172]. In the skin, oleic acid, along with other unsaturated FA, seems to be incorporated into the lipid moiety of Staphylococcus aureus Lpp, inducing an immune response against the pathogen [173].

Regarding conjugated PUFA, punicic acid has been shown to improve the immune system development, stimulate the CD4+ and CD8+ lymphocyte-mediated immunity and increase the immune response against viruses [174]. These immune boosting effects are due to nuclear peroxisome proliferator-activated receptor (PPAR) $\gamma$ - and $\delta$-dependent mechanisms, as punicic acid is able to act as an agonist of these receptors; in support, the loss of PPAR $\gamma$ in immune cells impaired its effects $[174,175]$. Moreover, punicic acid inhibited the TNF- $\alpha$-induced priming of ROS production by inhibiting the Ser345-p47phox phosphorylation and upstreaming kinase p38MAPK; likewise, it blocked 
the TNF- $\alpha$-induced release of myeloperoxidase from neutrophils, and decreased neutrophil-activation and ROS/MPO-mediated tissue damage in vivo [176]. Antinflammatory properties were found to be related to the activation of PPAR $\gamma$ and the suppressed expression of inflammatory genes (encoding cytokines, chemokines, cyclooxygenase, NO synthase, and metalloproteinases) [150].

Immunomodulatory properties of $\omega-6$ and $\omega-3$ PUFA have been highlighted in different preclinical models and have been associated with their ability to modulate the inflammatory process [177]. These fatty acids share common biosynthetic enzymes which mediate the production of different series of eicosanoids, starting from typical precursors, including dihomo- $\gamma$-linoleic acid (DGLA), arachidonic acid (AA) and eicosapentaenoic acid (EPA). Among prostanoids, three types of prostaglandins (PG), including PG1, PG2 and PG3, can be obtained. PG1 is associated with beneficial effects and lower inflammation, thus being considered as an antinflammatory prostanoid; conversely, PG2 has opposite behaviour, increasing inflammation, vasoconstriction and blood clotting. PG3 acts through a mixture of functions and is able to reduce the PG2-mediated inflammation [177].

Starting from DGLA, both anti-inflammatory PG1 and pro-inflammatory PG2, through the conversion into arachidonic acid, can be produced (Figure 7).
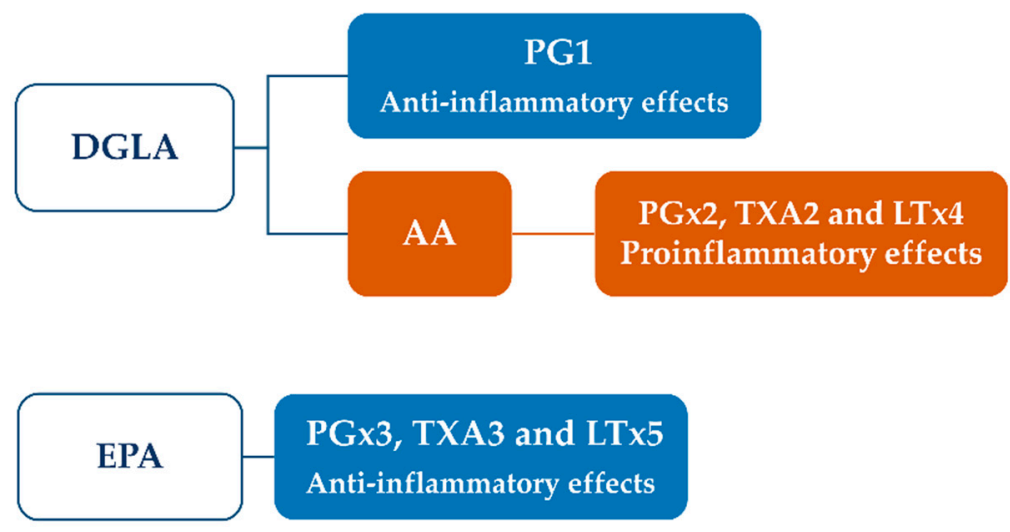

Figure 7. Role of $\omega-6$ and $\omega-3$ PUFA in the synthesis of proinflammatory or anti-inflammatory mediators.

This synthesis is controlled by the activity of $\Delta 5$-desaturase and $\Delta 6$-desaturase enzymes, which are often compromised during inflammatory conditions and diseases. It has been found that diets enriched in $\omega-3$ fatty acids are able to activate the conversion of DGLA into PG1, whereas low $\omega-3$ intake induces the conversion in AA with the synthesis of proinflammatory prostanoids [178].

AA can also be released by the cell membranes through the action of phospholipase A2 during cell injuries or changes in biomembrane composition, thus representing a physiological activator of inflammation as a defence response. AA and eicosapentaenoic acid (EPA) compete for the synthesis of different series of PG, mediated by cyclooxigenase, while 5-lipooxygenase (LOX) is involved in their conversion into thromboxanes and leukotrienes. Particularly, tromboxane A2 and leukotriene $\mathrm{B} 4$ are produced from AA, while tromboxane A3 and leukotriene B5 from EPA. EPA and DHA are also precursors of lipoxins, resolvins and protectins, which produced anti-inflammatory effects and regulate vascular tone and blood pressure [178]. Like punicic acid, the anti-inflammatory effects of EPA and DHA are mediated by the activation of the PPAR $\alpha / \gamma$ [179].

Despite the antinflammatory role of $\omega-3$ and $\omega$-6-based diets, AA increases the plasmatic levels of proinflammatory eicosanoids, associated with an increased incidence of allergic and inflammatory disorders and with excessive cell proliferation.

Anyhow, it is not clear the usefulness to select $\omega-3$ with respect to $\omega-6$ in the diet: a balance between $\omega-3$ and $\omega-6$ PUFA seems to be essential for mantaining ahealth status.

The ability of fatty acids to be incorporated in the cell membrane seems to represent a key mechanism accounting for the immunomodulating properties of $\omega-3$ and $\omega-6$ PUFA. Indeed, immune 
cells (i.e., T cells and neutrophils) can incorporate exogenous fatty acids into membrane with a lateration in the function of cell surface pattern recognition receptors [180].

Dietary $\omega-3$ PUFA has been shown able to modulate the macrophage function, through the activation of $G$ protein coupled receptors (GPR) and to induce a shift to an anti-inflammatory phenotype [49]. Modulating signalings through the GPR receptor activation can also affect leukocyte function. Likewise, an inhibition of the pro-inflammatory phenotype of dendritic cells and of the $\mathrm{T}$ cell responses has been reported [49]. They are also able to inhibit neutrophil and monocyte adhesion, depending on the activation of PPAR- $\alpha$ [49].

Conversely, $\omega-6$ PUFAs seem to promote inflammation, associated with incresead ROS levels, in neutrophils [49]. Particularly, linoleic acid increased the marginated pool of neutrophils in tissues by the induced expression of adhesion molecules; it also complexed with the anti-inflammatory molecule 1-antitrypsin, thus reducing LPS-induced IL-1 secretion in neutrophils [49]. On the whole, preclinical evidence highlighted that these fatty acids could increase neutrophil function, thus promoting innate immunity.

Regarding adaptive immunity, $\omega-3$ PUFA have been reported able to improve the mitogen-mediated activation of immune cells and to promote the development of a TH2-type immune response [180]. Moreover, an increased production of associated anti-inflammatory cytokines like IL-4, in spite of a reduction of pro-inflammatory TNF- $\alpha$, was found [180]. Similar effects were highlighted with both fish oil-enriched diets and the purified EPA and DHA [49].

The beneficial influence of $\omega-3$ PUFA has been highlighted also on epithelial cells during inflammation, being able to restore impaired barrier function and reduce the production of pro-inflammatory mediators [49]. Moreover, a strictly interplay between omega-3 fatty acids, immunity and gut microbiota has been reported and seems to be an essential factor to maintain the intestinal wall integrity. These effects have been ascribed to the ability of $\omega-3$ PUFA to positively affect the microbiota composition and increase the production of anti-inflammatory compounds, like short-chain fatty acids [181].

Although a major interest over the years has been focused on marine sources of $\omega$-3-enriched oils or on pure compounds, some plant species have been studied for their immunomodulating and anti-inflammatory properties, likely ascribable to $\omega-3$ and/or $\omega-6$ PUFA, although the major evidence has been highlighted for Linum usitatissimun L., Oenothera biennis L. and Borago officinalis L. [160,182,183].

The seed oil from L. usitatissimum, also known as flaxseed oil, has been reported to induce immunomodulating effects, likely through suppressing cell mediated immunity, without the involvement of humoral immunity. Being a rich source of ALA, its effects are mainly ascribed to this compound, although further studies suggested a possible contribution of bioactive phenolics [184]. Flaxseed oil was found to be effective in reducing skin inflammatory responses, although with a lower immunosuppressive power with respect to fish oil [185]. Moreover, it improved systemic and gut immunity, in a piglet model with intrauterine growth retardation: increased plasma concentration of immunoglobulin $\mathrm{G}$, decreased CD3+CD8+ T lymphocytes, and the downregulation of genes expression for proinflammatory factors have been reported [186].

Regarding O. biennis, the administration of the seed oil (namely, evening primrose oil) in animal models enhanced PGE1 synthesis in peritoneal macrophages, decreased PGE2 amounts in granulocytes, and suppressed the natural killer (NK) cell activity and lymphocyte proliferation; moreover, it decreased the serum levels of interferon $\gamma$ (IFN- $\gamma$ ) and MCP-1, while stimulating TNF- $\alpha$ [187-191]. Furthermore, anti-inflammatory effects have been found to be involved in the immunomodulation by evening primrose oil [160].

These effects were ascribed to the content of GLA, whose T-regulatory cell activity in autoimmune disease models was highlighted [192]. However, a contribution of LA to the antinflammatory effects seems to be likely; indeed, LA can itself modulate inflammation as it is metabolized by LOX to hydroxyoctadecadienoic acids (HODEs) and oxo-HODEs, characterized by antinflammatory properties [193]. 
Similarly, the seed oil from B. officinalis seeds produced immonomodulating and antinflammatory effects, likely through its GLA content [183]. A chemotactic migration of monocytes to necrotic site that differentiate into macrophages is associated with the administration of this product. Moreover, it is known to reduce the levels of proinflammatory cytokines, such as TNF- $\alpha$, and to promote PGE1 generation; a reduced expression of inflammatory genes, especially those of macrophages involved in atherosclerosis, has been reported too [183-194].

\subsection{Clinical Studies}

Clinical studies mainly focused on the effects of fatty acid-enriched diet on inflammation, although specific immune-based pathological conditions associated with inflammation were assessed too. Regarding MUFA, few studies are available, and results differ from those in animal models. Indeed, a MUFA-rich diet (with highly refined olive oil for 8 weeks) did not alter the immune function in healthy subjects; such effects could be due to the high amounts administered in animal models [164]. Conversely, clinical evidence about the immunomodulatory power of punicic acid in healthy or sick subjects is lacking [150].

The $\omega-3$ PUFA series and the relative enriched fish oils have been mainly evaluated for their immunomodulating and antinflammatory effects in humans. Although preclinical evidence highlighted their ability to influence both innate and adaptive immunity, the clinical relevance of these results remains to be clarified, due to lacking or inconclusive data [49].

Inadequacy of clinical results should be due to the different doses used in preclinical studies, wherein often high fatty acids levels were administered; moreover, other factors such as genetic and epigenetic heterogeneity of the recruited subjects, diet diversity, nutritional habits and microbiome can be considered as additional confounding factors [49].

Although limitations of clinical studies require further confirmation, $\omega-3$ PUFA intake produced significant clinical benefits and reduction of the symptoms in patients with autoimmune disorders, especially rheumatic diseases and systemic lupus erythematosus [195-197]. In support, low levels of PUFAs have been found in the serum of patients with rheumatic diseases [198]. Conversely, inconsistent results are reported for multiple sclerosis, thus the possible usefulness of these fatty acids as supportive therapy requires more clinical trials [199].

Regarding $\omega-6$ PUFA, although they are associated with possible increased inflammatory conditions, being arachidonic acid a presursor of proinflammatory prostanoids, such a risk is not confirmed by clinical evidence [200]. Indeed, studies in healthy human adults highlighted that an increased intake of these fatty acids did not induce inflammation; conversely, epidemiological evidence reported reduced inflammatory conditions [200]. The antinflammatory effects of LA have been reported too [193]. Similarly, increased LA intake was found to be not related to increased amounts of ARA and proinflammatory factors; however, an inverse correlation with EPA and DHA was reported [201]. This suggests that the interaction between $\omega$-e and $\omega-6$ series is regulated by complex mechanisms that requires further clarifications.

Major clinical studies have been performed using evening primrose oil (from the seeds of O. biennis), as a source of LA and GLA, in inflammatory diseases associated with immune system disorders, including atopic dermatitis, psoriasis, multiple sclerosis and rheumatoid arthritis. Standardized oils for the content in LA and ALA (for instance, Efamol is titred to contain 72\% LA and 9\% GLA) were usually used [202].

The treatment with evening primrose oil (4 and 7 weeks) produced clinical improvements in patients with atopic dermatitis, as revealed by measuring the SCORing atopic dermatitis [203]. Some beneficial effects were also reported in multiple schlerosis patients, although the few available studies limited the evidence in this disorder.

Conversely, evening primrose oil in combination with fish oil and vitamin E (Efamol Marine) failed to improve the symptoms of psoriasiac patients but produced antinflammatory effects [204]. Similarly, in association with $\omega-3$ fatty acids, it did not induce improvements in patients with 
rheumatoid arthritis [205]. A Cochrane revision highlighted moderate evidence for oils containing GLA (i.e., evening primrose, borage, or blackcurrant seed oil) to produce benefit in rheumatoid arthritis $[205,206]$. Evening primrose oil along with borage oil were not effective to treat eczema too [207]. Highly variable results were also obtained for borage oil in the treatment of atopic dermatitis, although, in all the studies, a moderate efficacy degree was displayed [208].

Regarding flaxseed oils, some clinical trials higlighted a significant improvement of inflammatory parameters in subjects with cardiovascular diseases non-associated with the immune system [209].

Reported studies, although performed in pathological conditions associated with immune system disfunction, did not give a direct measure of the immunomodulatory effects of the treatments. Furthermore, specific and high-quality studies are required for better characterizing the possible usefuleness of these PUFA-enriched oils as anti-inflammatory and immunomodulating treatments.

\section{Labdane Diterpenes}

\subsection{Chemical Features}

Labdane compounds have a molecular formula $\mathrm{C}_{20} \mathrm{H}_{38}$ with an average mass of $278.516 \mathrm{Da}$ (Figure 8). Labdane-related molecules have a hydrocarbon skeleton, originated from dual biosynthetic cyclization and/or rearrangement reactions, produced through the biosynthetic pathway of gibberellin phytohormones by the diterpene cyclases. The labane diterpenoids belong to a superfamily of natural products, in which the hydrocarbon skeleton might serve as privileged scaffolds for their biological activity [210].

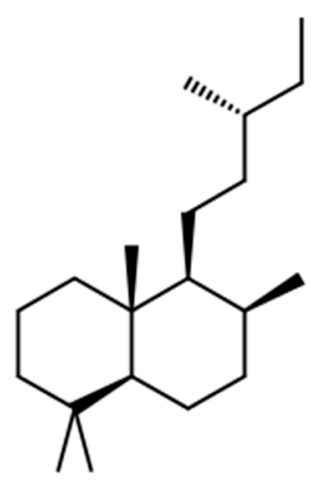

Figure 8. Chemical structure of the skeleton of labdane compound. The figure has been obtained using the ChemSpider ${ }^{\circledR}$ chemical structure database.

\subsection{Natural Occurrence}

Labdane diterpenes have been found in the various matrix of vegetal origin (leaves, rizomes, fruits, etc.) of different plants. In Table 1, some of them (where diterpenes have been found), their botanical family (in parentheses) and the part of plant of biological interest are reported.

Some labdane diterpenoids, isolated from plant matrix, include the following: andrographolide (Figure 9) (from Andrographis paniculata (Burm.f.) Nees) [211], labda-8(17), 12-diene-15, 16-dial (from Curcuma amada Roxb) [212], podoimbricatin C (a 12,17-cyclo-labdane diterpenoid from Dacrycarpus imbricatus (Blume) de Laub) [213] chapecoderins A-C (from Echinodorus macrophyllus (Kunth) Micheli), [214], (4R,5S,9S,10R)-13-des-ethyl-13-oxolabda-8(17),11E-dien-19-oic acid (from Juniperus oblonga M. Bieb) [215], leoheteronin D and leojaponin A (from Leonurus japonicus Houtt) [216], marrubasch A-F and marrubenol (from Marrubium aschersonii P.Magnus), marrulibanoside (from Marrubium globosum Boiss. and Balansa) [217], vitexlimolides A-C (from Vitex limonifolia Wall. ex C.B. Clarke) [218]. 


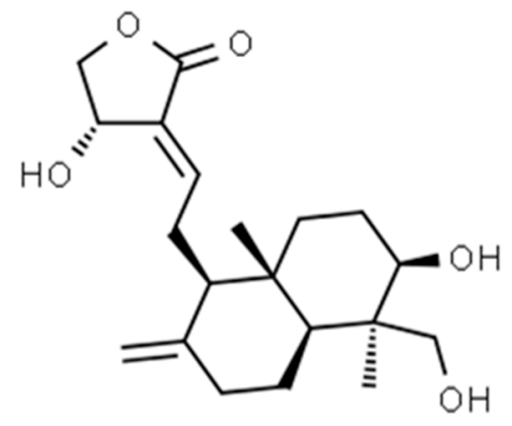

Figure 9. Chemical structure of andrographolide. This has been obtained using ChemSpider ${ }^{\circledR}$ chemical structure database.

\subsection{Pharmacological Properties: Preclinical Studies}

The body's defense responses can be improved through various properties induced by plants. Some of them, referring to the plants in Table 5, are shown below. For each plants and plant-derived nutraceutical, only properties potentially attributable to the labdane skeleton and useful to improve the immune system are reported.

Table 5. Examples of medicinal plants containing labdane diterpenoids, with immune system modulation activities.

\begin{tabular}{cccc}
\hline Plants & Family & $\begin{array}{c}\text { Part of the Plant of } \\
\text { Biological Interest }\end{array}$ & References \\
\hline Andrographis paniculata (Burm.f.) Nees & Acanthaceae & Aerial parts, roots & {$[211,219]$} \\
Curcuma amada Roxb & Zingiberaceae & Rizome & {$[212]$} \\
Dacricarpus imbricatus (Blume) de Laub & Podocarpaceae & Bark & {$[213]$} \\
Echinodorus macrophyllus (Kunth) Micheli & Alismataceae & Leaves & {$[214]$} \\
Juniperus oblonga M. Bieb & Cupressaceae & Berries & {$[215]$} \\
Leonurus japonicas Houtt & Lamiaceae & Aerial parts & {$[216]$} \\
Marrubium L. Spp. & Lamiaceae & Aerial parts & {$[217]$} \\
Vitex limonifolia Wall. ex C.B.Clarke & Lamiaceae & Leaves & {$[218]$} \\
\hline
\end{tabular}

As both inflammation (biological response of body tissues to harmful stimuli) and oxidative stress (imbalance between reactive oxygen species and a biological system's ability to detoxify/repair the resulting damage of the reactive intermediates) are the main self-defend methods to eliminate pathogens and protect living bodies, plants with antinflammatory and/or radical scavenger properties are considered too [211]. Indeed, labdane diterpenoids have recently gained greater attention from the scientific point of view, due to a wide range of biological activities, including the anti-inflammatory modulation of immune cell functions [217].

A. paniculata exhibited, in vitro and in vivo, various pharmacological activities, including antihyperglycemic, antiplatelet aggregation, anti-microbial, anti-inflammatory, anti-HIV, anti-cancer, anti-nociceptive activity, etc. It has also been used for autoimmune encephalomyelitis and, in Indian and Chinese medicine, for respiratory tract infections [217,219].

More recently, $A$. paniculata has been used to stimulate the immune system and treat myocardial ischemia [211]. A. paniculata inhibited interleukin (IL)-6, TNF- $\alpha$ mRNA, LPS-induced expression, and suppressed levels of TNF- $\alpha$, IL-1 $\beta$, JNK, C-reactive protein, and NF- $\mathrm{B}$ [211]. Many labdane diterpenoids compounds have been found to act on the latter. The activation of the NF- $\mathrm{kB}$ pathway leads to several physiological responses, including inflammatory or innate immune response [217].

In vitro, andrographolide (the main phytoconstituent of $A$. paniculata) can inhibit inflammation, by regulating protein expression (cytokines, chemokines) and by reducing immune cell infiltration. Andrographolide was shown to inhibit also oxidative stress by binding to adenosine A2A receptor, 
by inducing nuclear factor (erthroid-derived 2)-like 2 (Nrf2) translocation, and by increasing the expression of superoxide dismutase, catalase, glutathione reductase, glutathione peroxidase-2 [211]. These effects can contribute to the immunoregulatory activity of this plant-derived nutraceutical, as it can modulate the innate and adaptive immune responses by regulating macrophage phenotypic polarization and antibody productions [25]. Moreover, it was found to exert cytotoxic/anticancer effects on almost all types of tumour cell lines (human leukemia, renal tubular epithelial cells, breast cancer cells, etc.), mainly by cell cycle arrest, autophagy, cell death, anti-inflammatory and immune system mediated effects [220].

Other preclinical studies have highlighted pharmacological properties of labdane diterpenoidscontaining plants. Data are limited, and consequently also their preclinical evidence. Some examples are reported below.

C. amada, also known as mango ginger, and its labdane-diterpenoids have shown antiflammatory, antibacterial, insecticidal, antifungal, antipyretic, antioxidant, anticancer, and antitubercolar properties in preclinical trials [212].

D. imbricatus displayed cytotoxic and anti-neuroinflammatory activities, but it had no cytotoxic activity against human tumour cell lines [213].

E. macrophyllus, Brazilian plant, also known as "leather hat", is used as a methanolic (which contains mainly labane diterpenoids, steroids, alcaloids, etc.) or aqueous extract (rich in flavonoids) of the aerial parts, leaves in particular. In folk medicine, E. macrophyllus is used for various illnesses (respiratoy and urinary diseases, rheumatoid arthritis, atherosclerosis, etc.), as it has been shown to possess tissues protective activity and immunosuppressive effects (impaired secretion and function of B and/or T cells), on humoral or cellular immune responses and on autoimmune rheumatic diseases [221].

In in vitro/vivo studies, the aqueous extract of E. macrophyllus exhibited strong antinflammatory activities by decreasing rats paw edema, inflammatory exudates, infiltrate tissues, NO production, LTB4 release, and neutrophil migration [222]. In preclinical studies, the methanolic extract of E. macrophyllus was not cytotoxic, genotoxic, mutagenic, and no acute toxicity (up to the maximum dose of $2000 \mathrm{mg} / \mathrm{kg}$ b.w.) has been observed in tested animals [221]. However, the extrapolation of animal experiments to clinical practice must be done with caution [223].

Compounds from J. oblonga have shown anti-tumor effects, through moderate cytotoxicity against human tumor cell lines obtained from various human tissues, including: hepatocellular carcinoma (HepG2), breast cancer (MCF-7), and cervical carcinoma cancer (HeLa) [215]. The berries from J. oblonga also have antimicrobial activity and anti-inflammatory effects.

Labdane diterpenoid (e.g., leonurine), extracted from L. japonicus, exhibited cytotoxicity and cell cicle arrest against cancer cell lines and presented immunomodulatory and antinflammatory activities (suppresses TNF- $\alpha, \mathrm{NF}-\mathrm{kB}$, and down-regulated expression of iNOS, COX2, and conseguently PEG2 and NO levels) [216].

Marrubium spp. (aschersonii, globosum, etc.) have multiple actions, including antimicrobial and anti-inflammatory activities. Marrubasch A-F and marrubenol, isolated from the ethanolic extract of M. aschersonii, exhibited weak reduction in iNOS activity and, consequentely, NO production [217]. Marrulibanoside, obtained from the aerial parts of M. globosum, inhibited catalytic activity of iNOS and COX-2enzymes, and consequentely, the PEG2 and NO production.

V. limonifolia, in preclinical trial, have shown a strong antiviral activity against coxsackievirus B3, human rhinovirus 1B, and enterovirus 71 (EV71). All of them could be responsible for various illnesses, ranging from common cold, hand, foot, and mouth diseases, to acute flaccid paralysis [218].

\subsection{Clinical Studies}

The clinical efficacy of the medicinal plants, and plant-derived nutraceuticals discussed above are almost totally lacking. Only for A. paniculata there are some evidence in humans.

Andrographis extract (various and not standardized), andrographolide, and its derivatives have been studied in the treatment of various disease (multiple sclerosis, infection disease, gastro-intestinal 
upsets, respiratory ailments, pain), and in the maintenance of immune function. In this last context, it seemed to improve the response to cough and sore throat, shortening the sick leave/time to resolution [219]. The most interesting activity is the increase of CD4+ lymphocyte levels, in HIV-positive patients [211]. The increase in these lymphocytes testifies an improvement in the state of the immune system. Moreover, a Chinese product containing andrographolide improved the efficacy of glucocorticoids and immunoglobulin in patients with severe hand, food, and mouth disease.

However, andrographolide is considered a hazard, as it is irritating, and its injectable use is limited because it could induce allergic reactions (erythema, pruritus, etc.), which are sometimes life-threatening [211].

Preclinical data suggested that andrographolide could be responsible of pharmacokinetics interactions, as it induced CYP1A2 [219]. The European Medicines Agency (EMA) reports a possibility of causing reproductive toxicity of Andrographis extracts (decreases in sperm motility and counts) [219]. On the other hand, no major adverse effects have been reported for A. paniculata; only minor side effects, mainly gastrointestinal, are known [219].

Notably, even if $A$. paniculata presents numerous pharmacological properties, andrographolide possess poor solubility (principally in DMSO), which severely limits the possibility of achieving a therapeutic effect (if not properly formulated). Its better absorption could be achieved by nano-formulations (e.g., nano-emulsion, nano-capsules).

\section{Further Research}

Immunomodulation by plant-based nutraceuticals represents an interesting tool to be exploited for the treatment and preventing purposes of immune system disorders, due to their multiple bioactivities, well tolerability and good patient compliance. However, as often reported for several herbal medicinal products, some points require being underlined to improve the research in the field and provide solid evidence to support their rational use.

According to previous stated critical issues [224,225], herbal products under study must be characterized for the phytochemical composition, using validated analytical methodologies, and for the extraction procedures; moreover, the starting material should be fully defined in terms of origin (country and region), cultivation conditions, botanical identity and plant part. The content of specific compounds, used as analytical or active markers, should be determined too. These requirements are needed to ensure reproducible pharmacological/clinical activity and to compare different studies. Indeed, using nonstandardized phytocomplexes increases variability of the biological response, thus limiting the reliability and validity of the studies.

Furthermore, to assess the pharmacological activity of specific compounds, purity (at least 95\%) and identity should be characterized. Indeed, when assessed as mixtures, the subtle interactions which can be established among phytochemicals make it difficult to understand whether the observed benefits are attributable to a specific class or to the whole phytocomplex. For instance, both fatty acids and polyphenols can be involved in the immunomodulating effects of PUFA-enriched plant oils. Moreover, as found for both polysaccharides and fatty acids, among the same class, different subclasses can co-occur, thus contributing to the whole effects.

Regarding preclinical studies, detailed methodologies, including information about specific extraction process, the choice of the tested concentrations and experimental procedures, vehicle effects, and comparison with standard effective compounds (positive controls) should be reported.

In order to validate the "goodness" of the treatment, promising results in preclinical studies should be confirmed by clinical evidence of efficacy and lack of toxicological concerns for both the isolated compounds and the whole phytocomplex. At last, possible interactions with diet constituents or possible pharmacological treatments, as reported for andrographolide, which is a CYP1A2 inducer, should be considered.

As highlighted for a number of natural products, clinical evidence is a major challenge for plant-based immunomodulating nutraceuticals too, due to limited specific studies. 
Moreover, methodological quality of the available trials was overall poor, the studies often being not blinded, protocol unavailable and lacking the standardization of tested products, thus making the claimed effect difficult to be reproduced.

At last, standardized methodologies for systematic reviews and meta-analyses, such as the PRISMA guidelines [226], would allow a rational interpretation of the results and suggestions for future research.

\section{Conclusions}

Medicinal plants are rich sources of bioactive phytochemicals, characterized by multiple and often pleiotropic activities, which can be exploited both therapeutically and as nutraceutical strategies for preventive purposes. Among plant-based nutraceuticals, immunomodulators have been highlighted to be of interest as boosters of the immune system, to counteract infectious or exogenous injuries, immunosuppressor, to control the abnormal immune response occurring during autoimmune diseases, or as adjuvants, which contribute by modulating nonimmune targets.

In this review, we highlighted the scientific evidence about the immunomodulating properties of three emerging classes of nutraceuticals, including polysaccharides, fatty acids and labdane diterpenes. Some of them, especially polysaccharides and labdane diterpenes, act as immune system booster, while fatty acids (MUFA and PUFA) mainly act as immunosuppressor, although punicic acid (a conjugate PUFA) exhibited immunostimulant properties. To date, these products are mainly used as well-tolerated food supplements, although the clinical evidence about their modulation of the immune functions is still limited. More investigations of better quality and specificity could strengthen the validity of using these plant-derived nutraceuticals in the immune system modulation.

Author Contributions: Conceptualization, A.D.S., A.V. and S.D.G.; supervision, A.D.S., A.V. and S.D.G.; Writing-original draft, A.D.S., A.V. and S.D.G.; Writing-review and editing, A.D.S. All authors have read and agreed to the published version of the manuscript.

Funding: This research received no external funding.

Acknowledgments: A.D.S. and S.D.G. fellowships were funded by grants from Sapienza University (Ateneo 2019) and Regione Lazio. The Authors thank "Enrico and Enrica Sovena" Foundation (Italy) for supporting the study.

Conflicts of Interest: The authors declare no conflict of interest.

\section{References}

1. Maggini, S.; Pierre, A.; Calder, P.C. Immune Function and Micronutrient Requirements Change over the Life Course. Nutrients 2018, 10, 1531. [CrossRef]

2. Moser, M.; Leo, O. Key concepts in immunology. Vaccine 2010, 28, C2-C13. [CrossRef]

3. Kumar, D.; Romero, Y.; Schuck, K.N.; Smalley, H.; Subedi, B.; Fleming, S.D. Drivers and regulators of humoral innate immune responses to infection and cancer. Mol. Immunol. 2020, 121, 99-110. [CrossRef]

4. Wen, C.C.; Chen, H.M.; Yang, N.S. Developing Phytocompounds from Medicinal Plants as Immunomodulators. Adv. Bot. Res. 2012, 62, 197-272. [PubMed]

5. Durcan, L.; Petri, M. Immunomodulators in SLE: Clinical evidence and immunologic actions. J. Autoimmun. 2016, 74, 73-84. [CrossRef] [PubMed]

6. Mutgi, K.; Koo, J. Update on the role of systemic vitamin D in atopic dermatitis. Pediatr. Dermatol. 2013, 30, 303-307. [CrossRef] [PubMed]

7. Netea, M.G.; Giamarellos-Bourboulis, E.J.; Domínguez-Andrés, J. Trained Immunity: A Tool for Reducing Susceptibility to and the Severity of SARS-CoV-2 Infection. Cell 2020, 181, 969-977. [CrossRef]

8. Di Pasquale, A.; Preiss, S.; Tavares Da Silva, F.; Garçon, N. Vaccine Adjuvants: From 1920 to 2015 and beyond. Vaccines 2015, 3, 320-343. [CrossRef]

9. Coffman, R.L.; Sher, A.; Seder, R.A. Vaccine adjuvants: Putting innate immunity to work. Immunity 2010, 33, 492-503. [CrossRef]

10. Hui, D.S.; Lee, N.; Chan, P.K.; Beigel, J.H. The role of adjuvant immunomodulatory agents for treatment of severe influenza. Antiviral Res. 2018, 150, 202-216. [CrossRef] 
11. Temizoz, B.; Kuroda, E.; Ishii, K.J. Vaccine adjuvants as potential cancer immunotherapeutics. Int. Immunol. 2016, 28, 329-338. [CrossRef] [PubMed]

12. Dougan, M.; Dranoff, G. Immunotherapy of Cancer. In Innate Immune Regulation and Cancer Immunotherapy; Wang, R., Ed.; Springer: New York, NY, USA, 2012.

13. Pawelec, G.; Gupta, S. Editorial: Immunology of Aging. Front. Immunol. 2019, 10, 1614. [CrossRef]

14. Mohamed, S.I.A.; Jantan, I.; Haque, M.A. Naturally occurring immunomodulators with antitumor activity: An insight on their mechanisms of action. Int. Immunopharmacol. 2017, 50, 291-304. [CrossRef] [PubMed]

15. Zheng, D.; Liwinski, T.; Elinav, E. Interaction between microbiota and immunity in health and disease. Cell Res. 2020, 30, 492-506. [CrossRef] [PubMed]

16. Michel, J.; Mezouar, S.; Sereme, Y.; Chanez, P.; Vitte, J.; Dubus, J.C.; Chantran, Y.; Leone, M.; Mège, J.L.; Fabre, A.; et al. Microbiome and the immune system: From a healthy steady-state to allergy associated disruption. Hum. Microbiome J. 2018, 10, 11-20.

17. Mukherjee, P.K.; Nema, N.K.; Venkatesh, P.; Debnath, P.K. Changing scenario for promotion and development of Ayurveda-Way forward. J. Ethnopharmacol. 2012, 143, 424434. [CrossRef]

18. Wang, C.; Hou, Y.; Lv, Y.; Chen, S.; Zhou, X.; Zhu, R.; Wang, J.; Jia, W.; Wang, X. Echinacea purpurea Extract Affects the Immune System, Global Metabolome, and Gut Microbiome in Wistar Rats. J. Agric. Sci. 2017, 9, 1. [CrossRef]

19. Sun, Y.; Chen, S.; Wei, R.; Xei, X.; Wang, C.; Fan, S.; Zhang, X.; Su, J.; Liu, J.; Jia, W.; et al. Metabolome and gut microbiota variation with long-term intake of Panax ginseng extracts on rats. Food Funct. 2018, 9, 3547-3556. [CrossRef]

20. Chen, D.; Chen, G.; Ding, Y.; Wan, P.; Peng, Y.; Chen, C.; Ye, H.; Zeng, X.; Ran, L. Polysaccharides from the flowers of tea (Camellia sinensis L.) modulate gut health and ameliorate cyclophosphamide-induced immunosuppression. J. Funct. Food 2019, 61, 103470. [CrossRef]

21. Stohs, S.J.; Bagchi, D. Antioxidant, Anti-inflammatory, and Chemoprotective Properties of Acacia catechu Heartwood Extracts. Phytother. Res. 2015, 29, 818-824. [CrossRef]

22. Zhang, X.F.; Wang, H.M.; Song, Y.L.; Nie, L.H.; Wang, L.F.; Liu, B.; Shen, P.P.; Liu, Y. Isolation, structure elucidation, antioxidative and immunomodulatory properties of two novel dihydrocoumarins from Aloe vera. Bioorg. Med. Chem. Lett. 2016, 16, 949-953. [CrossRef] [PubMed]

23. Liu, C.; Cui, Y.; Pi, F.; Cheng, Y.; Guo, Y.; Qian, H. Extraction, Purification, Structural Characteristics, Biological Activities and Pharmacological Applications of Acemannan, a Polysaccharide from Aloe vera: A Review. Molecules 2019, 24, 1554. [CrossRef] [PubMed]

24. Pugh, N.; Ross, S.A.; El Sohly, M.A.; Pasco, D.S. Characterization of Aloeride, a new high-molecular-weight polysaccharide from Aloe vera with potent immunostimulatory activity. J. Agric. Food Chem. 2001, 49, 1030-1034. [CrossRef] [PubMed]

25. Wang, W.; Wang, J.; Dong, S.F.; Liu, C.H.; Italiani, P.; Sun, S.H.; Xu, J.; Boraschi, D.; Ma, S.P.; Qu, D. Immunomodulatory activity of andrographolide on macrophage activation and specific antibody response. Acta Pharmacol. Sin. 2010, 31, 191-201. [CrossRef] [PubMed]

26. Adorisio, S.; Fierabracci, A.; Muscari, I. Artocarpus tonkinensis Protects Mice Against Collagen-Induced Arthritis and Decreases Th17 Cell Function. Front. Pharmacol. 2019, 10, 503. [CrossRef] [PubMed]

27. Zheng, Y.; Ren, W.; Zhang, L.; Zhang, Y.; Liu, D.; Liu, Y. A Review of the Pharmacological Action of Astragalus Polysaccharide. Front. Pharmacol. 2020, 11, 349. [CrossRef]

28. Sharma, M.L.; Kaul, A.; Khajuria, A. Immunomodulatory activity of Boswellic acids (Pentacyclic Triterpene Acids) from Boswellia serrata. Phytother. Res 1996, 10, 107-112. [CrossRef]

29. Rahayu, R.P.; Prasetyo, R.A.; Purwanto, D.A.; Kresnoadi, U.; Iskandar, R.P.D.; Rubianto, M. The immunomodulatory effect of green tea (Camellia sinensis) leaves extract on immunocompromised Wistar rats infected by Candida albicans. Vet. World 2018, 11, 765-770. [CrossRef]

30. Gohil, K.J.; Patel, J.A.; Gajjar, A.K. Pharmacological Review on Centella asiatica: A Potential Herbal Cure-all. Ind. J. Pharm. Sci. 2010, 72, 546-556. [CrossRef]

31. Mollazadeh, H.; Cicero, A.F.G.; Blesso, C.N.; Pirro, M.; Majeed, M.; Sahebkar, A. Immune modulation by curcumin: The role of interleukin-10. Crit. Rev. Food Sci. Nutr. 2019, 59, 89-101. [CrossRef]

32. Guo, A.; He, D.; Xu, H.; Geng, C.; Zhao, J. Promotion of regulatory T cell induction by immunomodulatory herbal medicine licorice and its two constituents. Sci. Rep. 2016, 5, 14046. [CrossRef] [PubMed] 
33. Matyanga, C.M.J.; Morse, G.D.; Gundidza, M.; Nbachi, C.F.B. African potato (Hypoxis hemerocallidea): A systematic review of its chemistry, pharmacology and ethno medicinal properties. BMC Complement. Med. Ther. 2020, 20, 182. [CrossRef] [PubMed]

34. Jeba, R.C.; Vaidyanathan, R.A.M.A.; Rameshkumar, G. Efficacy of Ocimum basilicum for immunomodulatory activity in Wistar albino rat. Int. J. Pharm. Pharm. Sci. 2011, 3, 199-203.

35. Wagner, H.; Nörr, H.; Winterhoff, H. Plant daptogens. Phytomedicine 1994, 1, 63-76. [CrossRef]

36. Riaz, M.; Rahman, N.U.; Zia-Ul-Haq, M.; Jaffar, H.Z.E.; Manea, R. Ginseng: A dietary supplement as immune-modulator in various diseases. Trends Food Sci. Tech. 2019, 83, 12-30. [CrossRef]

37. Wael, S.; Watuguly, T.W.; Arini, I.; Smit, A.; Matdoan, N.; Prihati, D.R.; Sari, A.B.; Wahyudi, D.; Nuringtyas, T.R.; Wijayanti, N.; et al. Potential of Syzygium aromaticum (Clove) Leaf Extract on Immune Proliferation Response in Balb/c Mice Infected with Salmonella typhimurium. Clin. Med. Case Rep. 2018, 7, 613-627. [CrossRef]

38. Haque, M.A.; Jantan, I.; Abbas Bukhari, S.N. Tinospora species: An overview of their modulating effects on the immune system. J. Ethnopharmacol. 2017, 207, 67-85. [CrossRef]

39. Chandran, U.; Patwardhan, B. Network ethnopharmacological evaluation of the immunomodulatory activity of Withania somnifera. J. Ethnopharmacol. 2017, 197, 250-256. [CrossRef]

40. Kalra, R.; Kaushik, N. Withania somnifera (Linn.) Dunal: A review of chemical and pharmacological diversity. Phytochem. Rev. 2017, 16, 953-987. [CrossRef]

41. Ali, B.H.; Blunden, G.; Tanira, M.O.; Nemmar, A. Some phytochemical, pharmacological and toxicological properties of ginger (Zingiber officinale Roscoe): A review of recent research. Food Chem. Toxicol. 2008, 46, 409-420. [CrossRef]

42. Catanzaro, M.; Corsini, E.; Rosini, M.; Racchi, M.; Lanni, C. Immunomodulators Inspired by Nature: A Review on Curcumin and Echinacea. Molecules 2018, 23, 2778. [CrossRef]

43. Pillai, S.; Pillai, C.; Mitscher, L.A.; Cooper, R. Use of quantitative flow cytometry to measure ex vivo immunostimulant activity of Echinacea: The case for polysaccharides. J. Altern. Complement. Med. 2007, 13, 625-634. [CrossRef] [PubMed]

44. European Medicines Agency. Assessment Report on Echinacea purpurea (L.) Moench, Radix; EMA/HMPC/424584/2016; European Medicines Agency: Amsterdam, The Netherlands, 2017.

45. Kaur, P.; Makanjuola, V.O.; Arora, R.; Singh, B.; Arora, S. Immunopotentiating significance of conventionally used plant adaptogens as modulators in biochemical and molecular signalling pathways in cell mediated processes. Biomed. Pharmacother. 2017, 95, 1815-1829. [CrossRef] [PubMed]

46. Bachiega, T.F.; Orsatti, C.L.; Pagliarona, A.C.; Missima, F.; Sousa, J.P.B.; Bastos, J.K.; Sforcin, J.M. Th1/Th2 Cytokine Production by Clove-Treated Mice. Nat. Prod. Res. 2009, 23, 1552-1558. [CrossRef] [PubMed]

47. Akbar, S. Azadirachta indica A. Juss. (Meliaceae). In Handbook of 200 Medicinal Plants; Akbar, S., Ed.; Springer: Cham, Switzerland, 2020.

48. Cundell, R.D. Herbal Phytochemicals as Immunomodulators. Curr. Immunol. Rev. 2014, 10, 64-81. [CrossRef]

49. Radzikowska, U.; Rinaldi, A.O.; Çelebi Sözener, Z.; Karaguzel, D.; Wojcik, M.; Cypryk, K.; Akdis, M.; Akdis, C.A.; Sokolowska, M. The Influence of Dietary Fatty Acids on Immune Responses. Nutrients 2019, 11, 2990. [CrossRef]

50. Hoang, M.L.; Chen, C.H.; Chen, P.C.; Roberts, N.J.; Dickman, K.G.; Yun, B.H.; Turesky, R.J.; Pu, Y.S.; Vogelstein, B.; Papadopoulus, N.; et al. Aristolochic acid in the etiology of renal cell carcinoma. Cancer Epidemiol. Prev. Biomarkers 2016, 25, 1600-1608. [CrossRef]

51. Jantan, I.; Ahmad, W.; Bukhari, S.N.A. Plant-derived immunomodulators: An insight on their preclinical evaluation and clinical trials. Front. Plant Sci. 2015, 25, 655. [CrossRef]

52. Meng, X.; Zhou, J.; Zhao, C.N.; Gan, R.Y.; Li, H.B. Health Benefits and Molecular Mechanisms of Resveratrol: A Narrative Review. Foods 2020, 9, 340. [CrossRef]

53. Kuban-Jankowska, A.; Sahu, K.K.; Gorska, M.; Tuszynski, J.A.; Wozniak, M. Chicoric acid binds to two sites and decreases the activity of the YopH bacterial virulence factor. Oncotarget 2016, 7, 2229-2238. [CrossRef]

54. Tuyaerts, S.; Rombauts, K.; Everaert, T.; Van Nuffel, A.M.T.; Amant, F. A Phase 2 Study to Assess the Immunomodulatory Capacity of a Lecithin-based Delivery System of Curcumin in Endometrial Cancer. Front. Nutr. 2019, 5, 138. [CrossRef] [PubMed]

55. Jones, J.M. CODEX-aligned dietary fiber definitions help to bridge the 'fiber gap'. Nutr. J. 2014, 13, 34. [CrossRef] [PubMed] 
56. Ferreira, S.S.; Passos, C.P.; Madureira, P.; Vilanova, M.; Coimbra, M.A. Structure-function relationships of immunostimulatory polysaccharides: A review. Carbohydr. Polym. 2015, 132, 378-396. [CrossRef] [PubMed]

57. Singh, S.; Singh, G.; Arya, S.K. Mannans: An overview of properties and application in food products. Int. J. Biol. Macromol. 2018, 119, 79-95. [CrossRef]

58. Lee, J.S.; Kwon, J.S.; Yun, J.S.; Pahk, J.W.; Shin, W.C.; Lee, S.Y.; Hong, E.K. Structural characterization of immunostimulating polysaccharide from cultured mycelia of Cordyceps militaris. Carbohyd. Polym. 2010, 80, 1011-1017. [CrossRef]

59. Simões, J.; Madureira, P.; Nunes, F.M.; Domingues, M.D.R.; Vilanova, M.; Coimbra, M.A. Immunostimulatory properties of coffee mannans. Mol. Nutr. Food Res. 2009, 53, 1036-1043. [CrossRef]

60. Park, J.K.; Kim, Z.-H.; Lee, C.G.; Synytsya, A.; Jo, H.S.; Kim, S.O.; Park, J.W.; Park, Y.I. Characterization and immunostimulating activity of a water-soluble polysaccharide isolated from Haematococcus lacustris. Biotechnol. Bioproc. E 2011, 16, 1090-1098. [CrossRef]

61. Ohta, Y.; Lee, J.B.; Hayashi, K.; Fujita, A.; Park, D.K.; Hayashi, T. In vivo anti influenza virus activity of an immunomodulatory acidic polysaccharide isolated from Cordyceps militaris grown on germinated soybeans. J. Agric. Food Chem. 2007, 55, 10194-10199. [CrossRef]

62. Xie, G.; Schepetkin, I.A.; Siemsen, D.W.; Kirpotina, L.N.; Wiley, J.A.; Quinn, M.T. Fractionation and characterization of biologically-active polysaccharides from Artemisia tripartita. Phytochemistry 2008, 69, 1359-1371. [CrossRef]

63. Popov, S.V.; Ovodov, Y.S. Polypotency of the immunomodulatory effect of pectins. Biochemistry 2013, 78, 823-835. [CrossRef]

64. Yin, J.Y.; Chan, B.C.L.; Yu, H.; Lau, I.Y.K.; Han, X.Q.; Cheng, S.W.; Wong, C.K.; Lau, C.B.S.; Xie, M.Y.; Fung, K.P.; et al. Separation, structure characterization, conformation and immunomodulating effect of a hyperbranched heteroglycan from Radix Astragali. Carbohydr. Polym. 2012, 87, 667-675. [CrossRef]

65. Fang, X.; Chen, X. Structure elucidation and immunological activity of a novel pectic polysaccharide from the stems of Avicennia marina. Eur. Food Res. Technol. 2013, 236, 243-248. [CrossRef]

66. Stephanie, B.; Eric, D.; Sophie, F.M.; Christian, B.; Yu, G. Carrageenan from Solieria chordalis (Gigartinales): Structural analysis and immunological activities of the low molecular weight fractions. Carbohydr. Polym. 2010, 81, 448-460. [CrossRef]

67. Bhatia, S.; Rathee, P.; Sharma, K.; Chaugule, B.B.; Kar, N.; Bera, T. Immunomodulation effect of sulphated polysaccharide (porphyran) from Porphyra vietnamensis. Int. J. Biol. Macromol. 2013, 57, 50-56. [CrossRef] [PubMed]

68. Chlubnová, I.; Sylla, B.; Nugier-Chauvin, C.; Daniellou, R.; Legentil, L.; Kralová, B.; Ferrières, V. Natural glycans and glycoconjugates as immunomodulating agents. Nat. Prod. Rep. 2011, 28, 937-952. [CrossRef] [PubMed]

69. Benkeblia, N. Fructooligosaccharides and fructans analysis in plants and food crops. J. Chromatogr. A 2013, 1313, 54-61. [CrossRef] [PubMed]

70. Wu, X.; Dai, H.; Huang, L.; Gao, X.; Tsim, K.W.K.; Tu, P. A fructan, from Radix ophiopogonis, stimulates the proliferation of cultured lymphocytes: Structural and functional analyses. J. Nat. Prod. 2006, 69, 1257-1260. [CrossRef]

71. Akhtar, M.; Tariq, A.F.; Awais, M.M.; Iqbal, Z.; Muhammad, F.; Shahid, M.; Hiszczynska-Sawicka, E. Studies on wheat bran Arabinoxylan for its immunostimulatory and protective effects against avian coccidiosis. Carbohydr. Polym. 2012, 90, 333-339. [CrossRef]

72. Zhou, S.; Liu, X.; Guo, Y.; Wang, Q.; Peng, D.; Cao, L. Comparison of the immunological activities of arabinoxylans from wheat bran with alkali and xylanase-aided extraction. Carbohydr. Polym. 2010, 81, 784-789. [CrossRef]

73. Albuquerque, P.B.S.; de Oliveira, W.F.; Dos Santos Silva, P.M.; Dos Santos Correia, M.T.; Kennedy, J.F.; Coelho, L.C.B.B. Epiphanies of well-known and newly discovered macromolecular carbohydrates-A review. Int. J. Biol. Macromol. 2020, 156, 51-66. [CrossRef]

74. Schepetkin, I.A.; Quinn, M.T. Botanical polysaccharides: Macrophage immunomodulation and therapeutic potential. Int. Immunopharmacol. 2006, 6, 317-333. [CrossRef] [PubMed]

75. Korolenko, T.A.; Bgatova, N.P.; Vetvicka, V. Glucan and Mannan-Two Peas in a Pod. Int. J. Mol. Sci. 2019, 20, 3189. [CrossRef] [PubMed] 
76. Zhao, C.; Li, M.; Luo, Y.; Wu, W. Isolation and structural characterization of an immunostimulating polysaccharide from fuzi, Aconitum carmichaeli. Carbohydr. Res. 2006, 341, 485-491. [CrossRef] [PubMed]

77. Chandrashekar, P.M.; Prashanth, K.V.H.; Venkatesh, Y.P. Isolation, structural elucidation and immunomodulatory activity of fructans from aged garlic extract. Phytochemistry 2011, 72, 255-264. [CrossRef]

78. Simoes, J.; Nunes, F.M.; Domingues, P.; Coimbra, M.A.; Domingues, M.R. Mass spectrometry characterization of an Aloe vera mannan presentin immunostimulatory activity. Carbohydr. Polym. 2012, 90, 229-236. [CrossRef]

79. Mikkonen, K.S.; Tenkanen, M. Sustainable food packaging materials based on future biorefinery products: Xylans and mannans. Trends Food. Sci. Technol. 2012, 28, 90-102. [CrossRef]

80. Moretão, M.P.; Zampronio, A.R.; Gorin, P.A.J.; Iacomini, M.; Oliveira, M.B.M. Induction of secretory and tumoricidal activities in peritoneal macrophages activated by an acidic heteropolysaccharide (ARAGAL) from the gum of Anadenanthera colubrina (Angico branco). Immunol. Lett. 2004, 93, 189-197. [CrossRef]

81. Petkowicz, C.D.O.; Reicher, F.; Chanzy, H.; Taravel, F.R.; Vuong, R. Linear mannan in the endosperm of Schizolobium amazonicum. Carbohydr. Polym. 2001, 44, 107-112. [CrossRef]

82. Wang, X.S.; Liu, L.; Fang, J.N. Immunological activities and structure of pectin from Centella asiatica. Carbohydr. Polym. 2005, 60, 95-101. [CrossRef]

83. Sachslehner, A.; Foidl, G.; Foidl, N.; Gübitz, G.; Haltrich, D. Hydrolysis of isolated coffee mannan and coffee extract by mannanases of Sclerotium rolfsii. J. Biotechnol. 2000, 80, 127-134. [CrossRef]

84. Mikkonen, K.S.; Tenkanen, M.; Cooke, P.; Xu, C.; Rita, H.; Willför, S.; Holmbom, B.; Hicks, K.B.; Yadav, M.P. Mannans as stabilizers of oil-in-water beverage emulsions. LWT Food Sci. Technol. 2009, 42, 849-855. [CrossRef]

85. Zha, X.Q.; Luo, J.P.; Luo, S.Z.; Jiang, S.T. Structure identification of a new immunostimulating polysaccharide from the stems of Dendrobium huoshanense. Carbohydr. Polym. 2007, 69, 86-93. [CrossRef]

86. Luettig, B.; Steinmuller, C.; Gifford, G.E.; Wagner, H.; Lohmann-Matthes, M.-L. Macrophage activation by the polysaccharide arabinogalactan isolated from plant cell cultures of Echinacea purpurea. J. Natl. Cancer Inst. 1989, 81, 669-675. [CrossRef] [PubMed]

87. Wagner, H.; Stuppner, H.; Schäfer, W.; Zenk, M. Immunologically active polysaccharides of Echinacea purpurea cell cultures. Phytochemistry 1988, 27, 119-126. [CrossRef]

88. Holderness, J.; Schepetkin, I.A.; Freedman, B.; Kirpotina, L.N.; Quinn, M.T.; Hedges, J.F.; Jutila, M.A. Polysaccharides isolated from acaí fruit induce innate immune responses. PLoS ONE 2011, 6, e17301. [CrossRef] [PubMed]

89. Skyberg, J.A.; Rollins, M.F.; Holderness, J.S.; Marlenee, N.L.; Schepetkin, I.A.; Goodyear, A.; Dow, S.W.; Jutila, M.A.; Pascual, D.W. Nasal acai polysaccharides potentiate innate immunity to protect against pulmonary Francisella tularensis and Burkholderia pseudomallei infections. PLoS Pathog. 2012, 8, e1002587. [CrossRef] [PubMed]

90. Samuelsen, A.B.; Rieder, A.; Grimmer, S.; Michaelsen, T.E.; Knutsen, S.H. Immunomodulatory activity of dietary fiber: Arabinoxylan and mixed-linked Beta-glucan isolated from barley show modest activities in vitro. Int. J. Mol. Sci. 2011, 12, 570-587. [CrossRef]

91. Zhao, G.H.; Kan, J.Q.; Li, Z.X.; Chen, Z.D. Characterization and immunostimulatory activity of an $(1 \rightarrow 6)-$ $\alpha$-d-glucan from the root of Ipomoea batatas. Int. Immunopharmacol. 2005, 5, 1436-1445. [CrossRef]

92. Schepetkin, I.A.; Faulkner, C.L.; Nelson-Overton, L.K.; Wiley, J.A.; Quinn, M.T. Macrophage immunomodulatory activity of polysaccharides isolated from Juniperus scopolorum. Int. Immunopharmacol. 2005, 5, 1783-1799. [CrossRef]

93. Peng, X.M.; Huang, L.J.; Qi, C.H.; Zhang, Y.X.; Tian, G.Y. Studies on chemistry and immunomodulating mechanism of aglycoconjugate from Lycium barbarum L. Chin. J. Chem. 2001, 19, 1190-1197. [CrossRef]

94. Sun, L.; Peng, X.X.; Sun, P.; Shi, J.H.; Yuan, X.W.; Zhu, J.J.; Tai, G.; Zhou, Y. Structural characterization and immunostimulatory activity of a novel linear $\alpha-(1 \rightarrow 6)$ - d-glucan isolated from Panax ginseng C. A. Meyer. Glycoconj. J. 2012, 29, 357-364. [CrossRef] [PubMed]

95. Willför, S.; Sundberg, K.; Tenkanen, M.; Holmbom, B. Spruce-derived mannans-A potential raw material for hydrocolloids and novel advanced natural materials. Carbohydr. Polym. 2008, 72, 197-210. [CrossRef]

96. Dourado, F.; Madureira, P.; Carvalho, V.; Coelho, R.; Coimbra, M.A.; Vilanova, M.; Mota, M.; Gama, F.M. Purification, structure and immunobiological activity of an arabinan-rich pectic polysaccharide from the cell walls of Prunus dulcis seeds. Carbohydr. Res. 2004, 339, 2555-2566. [CrossRef] [PubMed] 
97. Guo, R.; Ai, L.; Cao, N.; Ma, J.; Wu, Y.; Wu, J.; Sun, X. Physicochemical properties and structural characterization of a galactomannan from Sophora alopecuroides L. seeds. Carbohydr. Polym. 2016, 140, 451-460. [CrossRef] [PubMed]

98. Xie, G.; Schepetkin, I.A.; Quinn, M.T. Immunomodulatory activity of acidic polysaccharides isolated from Tanacetum vulgare L. Int. Immunopharmacol. 2007, 7, 1639-1650. [CrossRef] [PubMed]

99. Nair, P.K.R.; Rodriguez, S.; Ramachandran, R.; Alamo, A.; Melnick, S.J.; Escalon, E.; Garcia, P.I., Jr.; Wnuk, S.F.; Ramachandran, C. Immune stimulating properties of a novel polysaccharide from the medicinal plant Tinospora cordifolia. Int. Immunopharmacol. 2004, 4, 1645-1659. [CrossRef]

100. Ramesh, H.P.; Yamaki, K.; Tsushida, T. Effect of fenugreek (Trigonella foenum-graecum L.) galactomannan fractions on phagocytosis in rat macrophages and on proliferation and IgM secretion in HB4C5 cells. Carbohydr. Polym. 2002, 50, 79-83. [CrossRef]

101. Yin, M.; Zhang, Y.; Li, H. Advances in Research on Immunoregulation of Macrophages by Plant Polysaccharides. Front. Immunol. 2019, 10, 145. [CrossRef]

102. Yao, J.F.; Wang, Z.X.; Zhang, X.Y.; Zhang, R.F. Study on immunomodulatory effect of Astragalus Polysaccharide on mice peritoneal macrophage. J. Henan Univ. 2005, 24, 34-36.

103. Lee, K.Y.; Jeon, Y.J. Macrophage activation by polysaccharide isolated from Astragalus membranaceus. Int. Immunopharm. 2005, 5, 1225-1233. [CrossRef]

104. Eman, Z.; Engy, R.; Fatma, A.; Hebata, A.M.; Tarek, I. Effects of dietary Astragalus polysaccharides (APS) on growth performance, immunological parameters, digestive enzymes, and intestinal morphology of Nile tilapia (Oreochromis niloticus). Fish Shellfish Immunol. 2014, 38, 149-157.

105. Qin, Q.; Niu, J.; Wang, Z.; Xu, W.; Qiao, Z.; Gu, Y. Astragalus membranaceus extract activates immune response in macrophages via heparanase. Molecules 2012, 17, 7232-7240. [CrossRef] [PubMed]

106. Shin, M.S.; Park, S.B.; Shin, K.S. Molecular mechanisms of immunomodulatory activity by polysaccharide isolated from the peels of Citrus unshiu. Int. J. Biol. Macromol. 2018, 112, 576-583. [CrossRef] [PubMed]

107. Sahasrabudhe, N.M.; Beukema, M.; Tian, L.; Troost, B.; Scholte, J.; Bruininx, E.; Bruggeman, G.; van den Berg, M.; Scheurink, A.; Schols, H.A.; et al. Dietary fiber pectin directly blocks toll-like receptor 2-1 and prevents doxorubicin-induced ileitis. Front. Immunol. 2018, 9, 383. [CrossRef] [PubMed]

108. Cai, Y.; Folkerts, J.; Folkerts, G.; Maurer, M.; Braber, S. Microbiota-dependent and -independent effects of dietary fibre on human health. Br. J. Pharmacol. 2020, 177, 1363-1381. [CrossRef] [PubMed]

109. Li, Y.; Wang, Y.; Wu, Y.; Wang, B.; Chen, X.; Xu, X.; Chen, H.; Li, W.; Xu, X. Echinacea purpurea extracts promote murine dendritic cell maturation by activation of JNK, p38 MAPK and NF-kB pathways. Dev. Comp. Immunol. 2017, 73, 21-26. [CrossRef]

110. Li, R.; Chen, W.; Wang, W.; Tian, W.; Zhang, X. Extraction, characterization of Astragalus polysaccharides and its immune modulating activities in rats with gastric cancer. Carbohydr. Polym. 2009, 78, 738-742. [CrossRef]

111. Li, J.; Zhong, Y.; Li, H.; Zhang, N.; Ma, W.; Cheng, G.; Liu, F.; Liu, F.; Xu, J. Enhancement of Astragalus polysaccharide on the immune responses in pigs inoculated with foot-and-mouth disease virus vaccine. Int. J. Biol. Macromol. 2011, 49, 362-368. [CrossRef]

112. Liu, W.H.; Zhang, J.Z.; Liu, S.J.; Qiu, H.N.; Guo, J.X.; Liu, B. Effect of radix astragali drug serum on NK cell activity and expression of KLRK1. Prog. Mod. Biomed. 2014, 14, 4637-4640.

113. Cao, L.; Liu, X.; Qian, T.; Sun, G.; Guo, Y.; Chang, F.; Zhou, S.; Sun, X. Antitumor andimmunomodulatory activity of arabinoxylans: A major constituent of wheatbran. Int. J. Biol. Macromol. 2011, 48, 160-164. [CrossRef]

114. Ghoneum, M.; Abedi, S. Enhancement of natural killer cell activity of agedmice by modified arabinoxylan rice bran (MGN-3/Biobran). J. Pharm. Pharmacol. 2004, 56, 1581-1588. [CrossRef] [PubMed]

115. Shao, B.M.; Xu, W.; Dai, H.; Tu, P.; Li, Z.; Gao, X.M. A study on the immune receptors for polysaccharides from the roots of Astragalus membranaceus, a Chinese medicinal herb. Biochem. Biophys. Res. Commun. 2004, 320, 1103-1111. [CrossRef] [PubMed]

116. Fan, Y.; Hu, Y.; Wang, D.; Liu, J.; Zhang, J.; Zhao, X.; Liu, X.; Liu, C.; Yuan, J.; Ruan, S. Effects of Astragalus polysaccharide liposome on lymphocyte proliferation in vitro and adjuvanticity in vivo. Carbohydr. Polym. 2012, 88, 68-74. [CrossRef] 
117. Hong, H.; Kim, J.; Lim, T.; Song, Y.; Cho, C.; Jang, M. Mixing ratio optimization for functional complex extracts of Rhodiola crenulata, Panax quinquefolius, and Astragalus membranaceus using mixture design and verification of immune functional efficacy in animal models. J. Funct. Foods 2018, 40, 447-454. [CrossRef] [PubMed]

118. Abuelsaad, A.S. Supplementation with Astragalus polysaccharides alters Aeromonas-induced tissue-specific cellular immune response. Microb. Pathog. 2014, 66, 48-56. [CrossRef]

119. Novak, M.; Vetvicka, V. Beta-glucans, history, and the present: Immunomodulatory aspects and mechanisms of action. J. Immunotoxicol. 2008, 5, 47-57. [CrossRef]

120. Aguilar, J.C.; Rodriguez, E.G. Vaccine adjuvants revisited. Vaccine 2007, 25, 3752-3762. [CrossRef]

121. Honda-Okubo, Y.; Saade, F.; Petrovsky, N. AdvaxTM, a polysaccharide adjuvant derived from delta inulin, provides improved influenza vaccine protection through broad-based enhancement of adaptive immune responses. Vaccine 2012, 30, 5373-5381. [CrossRef]

122. Saade, F.; Honda-Okubo, Y.; Trec, S.; Petrovsky, N. A novel hepatitis B vaccine containing AdvaxTM, a polysaccharide adjuvant derived from delta inulin, induces robust humoral and cellular immunity with minimal reactogenicity in preclinical testing. Vaccine 2013, 31, 1999-2007. [CrossRef]

123. Du, X.; Zhao, B.; Li, J.; Cao, X.; Diao, M.; Feng, H.; Chen, X.; Chen, Z.; Zeng, X. Astragalus polysaccharides enhance immune responses of HBV DNA vaccination via promoting the dendritic cell maturation and suppressing Treg frequency in mice. Int. Immunopharmacol. 2012, 14, 463-470. [CrossRef]

124. Vassilaros, S.; Tsibanis, A.; Tsikkinis, A.; Pietersz, G.A.; McKenzie, I.F.; Apostolopoulos, V. Up to 15-year clinical follow-up of a pilot Phase III immunotherapy study in stage II breast cancer patients using oxidized mannan-MUC1. Immunotherapy 2013, 5, 1177-1182. [CrossRef] [PubMed]

125. Kjaerup, R.M.; Dalgaard, T.S.; Norup, L.R.; Bergman, I.M.; Sørensen, P.; Juul-Madsen, H.R. Adjuvant effects of mannose-binding lectin ligands on the immune response to infectious bronchitis vaccine in chickens with high or low serum mannose-binding lectin concentrations. Immunobiology 2014, 219, 263-274. [CrossRef] [PubMed]

126. Luu, M.; Visekruna, A. Short-chain fatty acids: Bacterial messengers modulating the immunometabolism of T cells. Eur. J. Immunol. 2019, 9, 842-848. [CrossRef] [PubMed]

127. Koh, A.; De Vadder, F.; Kovatcheva-Datchary, P.; Backhed, F. From dietary fiber to host physiology: Short-chain fatty acids as key bacterial metabolites. Cell 2016, 165, 1332-1345. [CrossRef] [PubMed]

128. Segain, J.P.; Raingeard de la Bletiere, D.; Bourreille, A.; Leray, V.; Gervois, N.; Rosales, C.; Ferrier, L.; Bonnet, C.; Blottière, H.M.; Galmiche, J.P. Butyrate inhibits inflammatory responses through NFkappaB inhibition: Implications for Crohn's disease. Gut 2000, 47, 397-403. [CrossRef]

129. Kim, M.H.; Kang, S.G.; Park, J.H.; Yanagisawa, M.; Kim, C.H. Shortchain fatty acids activate GPR41 and GPR43 on intestinal epithelial cells to promote inflammatory responses in mice. Gastroenterology 2013, 145, 396-406. [CrossRef]

130. Jiang, C.M.; Zhang, M.; Sun, Z. Addition of astragalus into peritoneal dialysate improve peritoneal macrophages function in CAPD patients. J. Med. Postgrad. 2005, 18, 135-138.

131. Ji, X.Q.; Du, J.F.; Chen, G. Comparison of perioperative immune function status in colorectal cancer patients and immune regulatory function of drugs. Pract. J. Cancer 2011, 26, 331-334.

132. Shi, X.S.; Sun, Z.X. Influences of astragalus Injection on clinical efficacy and cellular immune function in patients of bronchial asthma with acute exacerbation. Chin. J. Exp. Trad. Med. Form. 2012, 18, 293-296.

133. Schwarz, E.; Parlesak, A.; Henneicke-von Zepelin, H.H.; Bode, J.C.; Bode, C. Effect of oral administration of freshly pressed juice of Echinacea purpurea on the number of various subpopulations of B- and T-lymphocytes in healthy volunteers: Results of a double-blind, placebo-controlled cross-over study. Phytomedicine 2005, 12, 625-631. [CrossRef]

134. Brinkeborn, R.M.; Shah, D.V.; Degenring, F.H. Echinaforce and other Echinacea fresh plant preparations in the treatment of the common cold. A randomized, placebo controlled, double-blind clinical trial. Phytomedicine 1999, 6, 1-6. [CrossRef]

135. Karsch-Völk, M.; Barrett, B.; Kiefer, D.; Bauer, R.; Ardjomand-Woelkart, K.; Linde, K. Echinacea for preventing and treating the common cold. Cochrane Database Syst. Rev. 2014, 2. [CrossRef] [PubMed]

136. Richter, J.; Svozil, V.; Kral, V.; Rajnohova Dobiasova, L.; Stiborova, I.; Vetvicka, V. Clinical trials of yeast-derived beta-(1,3) glucan in children: Effects on innate immunity. Ann. Transl. Med. 2014, 2, 15. [PubMed] 
137. Richter, J.; Svozil, V.; Kral, V.; Rajnohova Dobiasova, L.; Vetvicka, V. beta-glucan affects mucosal immunity in children with chronic respiratory problems under physical stress: Clinical trials. Ann. Transl. Med. 2015, 3,52 .

138. Vetvicka, V.; Richter, J.; Svozil, V.; Rajnohova Dobiasova, L.; Kral, V. Placebo-driven clinical trials of yeast-derived beta-(1-3) glucan in children with chronic respiratory problems. Ann. Transl. Med. 2013, 1, 26.

139. Varricchio, A.M.; Capasso, M.; Della Volpe, A.; Malafronte, L.; Mansi, N.; Varricchio, A.; Ciprandi, G. Resveratrol plus carboxymethyl- $\beta$-glucan in children with recurrent respiratory infections: A preliminary and real-life experience. Ital. J. Pediatr. 2014, 40, 93. [CrossRef]

140. Baldassarre, M.E.; Di Mauro, A.; Labellarte, G.; Pignatelli, M.; Fanelli, M.; Schiavi, E.; Mastromarino, P.; Capozza, M.; Panza, R.; Laforgia, N. Resveratrol plus carboxymethyl- $\beta$-glucan in infants with common cold: A randomized double-blind trial. Heliyon 2020, 6, e03814. [CrossRef]

141. Miraglia Del Giudice, M.; Maiello, N.; Capristo, C.; Alterio, E.; Capasso, M.; Perrone, L.; Ciprandi, G. Resveratrol plus carboxymethyl- $\beta$-glucan reduces nasal symptoms in children with pollen-induced allergic rhinitis. Curr. Med. Res. Opin. 2014, 30, 1931-1935. [CrossRef]

142. Fahy, E.; Subramaniam, S.; Murphy, R.C.; Nishijima, M.; Raetz, C.R.; Shimizu, T.; Spener, F.; van Meer, G.; Wakelam, M.J.; Dennis, E.A. Update of the LIPID MAPS comprehensive classification system for lipids. J. Lipid Res. 2009, 50, 9-14. [CrossRef]

143. Chow, C. Fatty Acids in Foods and Their Health Implications, 3rd ed.; CRC Press: Boca Raton, FL, USA, 2007; pp. 1-17.

144. Feng, W.; Ao, H.; Peng, C. Gut Microbiota, Short-Chain Fatty Acids, and Herbal Medicines. Front. Pharmacol. 2018, 9, 1354. [CrossRef]

145. Oteng, A.B.; Kersten, S. Mechanisms of Action of trans Fatty Acids. Adv. Nutr. 2020, 11, 697-708. [CrossRef] [PubMed]

146. Burdge, G.C. Polyunsaturated fatty acid biosynthesis and metabolism in adult mammals. In Polyunsaturated Fatty Acid Metabolism, 1st ed.; Burdge, G.C., Ed.; Elsevier Inc.: New York, NY, USA, 2018; pp. 15-30.

147. Hageman, J.H.; Danielsen, M.; Nieuwenhuizen, A.G.; Feitsma, A.L.; Dalsgaard, T.K. Comparison of bovine milk fat and vegetable fat for infant formula: Implications for infant health. Int. Dairy J. 2019, 92, 37-49. [CrossRef]

148. Arkcoll, D. Laurie oil resources. Econ. Bot. 1988, 42, 195-205. [CrossRef]

149. Fattore, E.; Fanelli, R. Palm oil and palmitic acid: A review on cardiovascular effects and carcinogenicity. Int. J. Food Sci. Nutr. 2013, 64, 648-659. [CrossRef] [PubMed]

150. Aruna, P.; Venkataramanamma, D.; Singh, A.K.; Singh, R.P. Health benefits of punicic acid: A review. Compr. Rev. Food Sci. Food Saf. 2016, 15, 16-27. [CrossRef]

151. Servili, M.; Sordini, B.; Esposto, S.; Urbani, S.; Veneziani, G.; Di Maio, I.; Selvaggini, R.; Taticchi, A. Biological Activities of Phenolic Compounds of Extra Virgin Olive Oil. Antioxidants 2013, 3, 1-23. [CrossRef]

152. Choi, S.G.; Won, S.R.; Rhee, H.I. Oleic Acid and Inhibition of Glucosyltransferase. In Olives and Olive Oil in Health and Disease Prevention, 1st ed.; Preedy, V.R., Watson, R.R., Eds.; Academic Press: Cambridge, MA, USA, 2010; pp. 1375-1383.

153. Saini, R.K.; Keum, Y.S. Omega-3 and omega-6 polyunsaturated fatty acids: Dietary sources, metabolism, and significance-A review. Life Sci. 2018, 203, 255-267. [CrossRef]

154. Lachman, J.; Hejtmánková, A.; Taborsky, J.; Kotíková, Z.; Pivec, V.; Střalková, R.; Vollmannová, A.; Bojňanská, T.; Dědina, M. Evaluation of oil content and fatty acid composition in the seed of grapevine varieties. LWT Food Sci.Technol. 2015, 63, 620-625. [CrossRef]

155. Nath, U.K.; Kim, H.-T.; Khatun, K.; Park, J.I.; Kang, K.K.; Nou, I.S. Modification of fatty acid profiles of rapeseed (Brassica napus L.) oil for using as food, industrial feed-stock and biodiesel. Plant Breed. Biotechnol. 2016, 4, 123-134. [CrossRef]

156. Yoshime, L.T.; de Melo, I.L.P.; Sattler, J.A.G.; de Carvalho, E.B.T.; Mancini-Filho, J. Bitter gourd (Momordica charantia L.) seed oil as a naturally rich source of bioactive compounds for nutraceutical purposes. Nutrire 2016, 41, 12. [CrossRef]

157. Parikh, M.; Netticadan, T.; Pierce, G.N. Flaxseed: Its bioactive components and their cardiovascular benefits. Am. J. Physiol. Heart Circ. Physiol. 2018, 314, H146-H159. [CrossRef] [PubMed]

158. Asif, M. Health effects of omega-3,6,9 fatty acids: Perilla frutescens is a good example of plant oils. Orient. Pharm. Exp. Med. 2011, 11, 51-59. [CrossRef] [PubMed] 
159. Guil-Guerrero, J.L.; Gómez-Mercado, F.; Ramos-Bueno, R.P.; González-Fernández, M.J.; Urrestarazu, M.; Jiménez-Becker, S.; de Bélair, G. Fatty acid profiles and sn -2 fatty acid distribution of $\gamma$-linolenic acid-rich Borago species. J. Food Compos. Anal. 2018, 66, 74-80. [CrossRef]

160. Timoszuk, M.; Bielawska, K.; Skrzydlewska, E. Evening Primrose (Oenothera biennis) Biological Activity Dependent on Chemical Composition. Antioxidants 2018, 7, 108. [CrossRef]

161. Farinon, B.; Molinari, R.; Costantini, L.; Merendino, N. The Seed of Industrial Hemp (Cannabis sativa L.): Nutritional Quality and Potential Functionality for Human Health and Nutrition. Nutrients 2020, 12, 1935. [CrossRef]

162. Traitler, H.; Winter, H.; Richli, U.; Ingenbleek, Y. Characterization of gamma-linolenic acid in Ribes seed. Lipids 1984, 19, 923-928. [CrossRef]

163. Kim, D.E.; Shang, X.; Assefa, A.D.; Keum, Y.S.; Saini, R.K. Metabolite profiling of green, green/red, and red lettuce cultivars: Variation in health beneficial compounds and antioxidant potential. Food Res. Int. 2018, 105, 361-370. [CrossRef]

164. Yaqoob, P. Monounsaturated fatty acids and immune function. Eur. J. Clin. Nutr. 2002, 56, S9-S13. [CrossRef]

165. Jeffery, N.M.; Cortina, M.; Newsholme, E.A.; Calder, P.C. Effects of variations in the proportions of saturated, monounsaturated and polyunsaturated fatty acids in the rat diet on spleen lymphocyte functions. Br. J. Nutr. 1997, 77, 805-823. [CrossRef]

166. Mastrangelo, A.M.; Jeitner, T.M.; Eaton, J.W. Oleic acid increases cell surface expression and activity of CD11b on human neutrophils. J. Immunol. 1998, 161, 4268-4275.

167. Ferrante, A.; Goh, D.; Harvey, D.P.; Robinson, B.S.; Hii, C.S.; Bates, E.J.; Hardy, S.J.; Johnson, D.W.; Poulos, A. Neutrophil migration inhibitory properties of polyunsaturated fatty acids. The role of fatty acid structure, metabolism, and possible second messenger systems. J. Clin. Investig. 1994, 93, 1063-1070. [CrossRef] [PubMed]

168. Llado, V.; Gutierrez, A.; Martinez, J.; Casas, J.; Teres, S.; Higuera, M.; Galmés, A.; Saus, C.; Besalduch, J.; Busquets, X.; et al. Minerval induces apoptosis in Jurkat and other cancer cells. J. Cell. Mol. Med. 2010, 14, 659-670. [CrossRef] [PubMed]

169. Cury-Boaventura, M.F.; Pompeia, C.; Curi, R. Comparative toxicity of oleic acid and linoleic acid on Jurkat cells. Clin. Nutr. 2004, 23, 721-732. [CrossRef] [PubMed]

170. Cury-Boaventura, M.F.; Pompeia, C.; Curi, R. Comparative toxicity of oleic acid and linoleic acid on Raji cells. Nutrition 2005, 21, 395-405. [CrossRef]

171. Kim, D.H.; Cho, Y.M.; Lee, K.H.; Jeong, S.W.; Kwon, O.J. Oleate protects macrophages from palmitate-induced apoptosis through the downregulation of CD36 expression. Biochem. Biophys. Res. Commun. 2017, 488, 477-482. [CrossRef]

172. Wu, H.; Weidinger, C.; Schmidt, F.; Keye, J.; Friedrich, M.; Yerinde, C.; Willimsky, G.; Qin, Z.; Siegmund, B.; Glauben, R. Oleate but not stearate induces the regulatory phenotype of myeloid suppressor cells. Sci. Rep. 2017, 7, 7498. [CrossRef]

173. Nguyen, M.T.; Hanzelmann, D.; Härtner, T.; Peschel, A.; Götz, F. Skin-Specific Unsaturated Fatty Acids Boost the Staphylococcus aureus Innate Immune Response. Infect. Immun. 2015, 84, 205-215. [CrossRef]

174. Viladomiu, M.; Hontecillas, R.; Lu, P.; Bassaganya-Riera, J. Preventive and prophylactic mechanisms of action of pomegranate bioactive constituents. Evid. Based Complement. Alternat. Med. 2013, 2013, 789764. [CrossRef]

175. Yuan, G.; Chen, X.; Li, D. Modulation of peroxisome proliferator-activated receptor gamma(PPAR $\gamma)$ by conjugated fatty acid in obesity and inflammatory bowel disease. J. Agric. Food Chem. 2015, 25, 1883-1895. [CrossRef]

176. Boussetta, T.; Raad, H.; Lettéron, P.; Gougerot-Pocidalo, M.A.; Marie, J.C.; Driss, F.; El-Benna, J. Punicic acid a conjugated linolenic acid inhibits TNFalpha-induced neutrophil hyperactivation and protects from experimental colon inflammation in rats. PLoS ONE 2009, 4, e6458. [CrossRef]

177. Lorente-Cebrián, S.; Costa, A.G.V.; Navas-Carretero, S.; Zabala, M.; Martínez, J.A.; Moreno-Aliaga, M.J. Role of omega-3 fatty acids in obesity, metabolic syndrome, and cardiovascular diseases: A review of the evidence. J. Physiol. Biochem. 2013, 69, 633-651. [CrossRef] [PubMed]

178. Calder, P.C. Polyunsaturated fatty acids and inflammation. Biochem. Soc. Trans. 2005, 33, 423-427. [CrossRef] [PubMed] 
179. Echeverria, F.; Ortiz, M.; Valenzuela, R.; Videla, L.A. Long-chain polyunsaturated fatty acids regulation of PPARs, signaling: Relationship to tissue development and aging. Prostaglandins Leukot. Essent. Fat Acids. 2016, 114, 28-34. [CrossRef] [PubMed]

180. Kumar, N.G.; Contaifer, D.; Madurantakam, P.; Carbone, S.; Price, E.T.; Van Tassell, B.; Brophy, D.F.; Wijesinghe, D.S. Dietary Bioactive Fatty Acids as Modulators of Immune Function: Implications on Human Health. Nutrients 2019, 11, 2974. [CrossRef] [PubMed]

181. Costantini, L.; Molinari, R.; Farinon, B.; Merendino, N. Impact of Omega-3 Fatty Acids on the Gut Microbiota. Int. J. Mol. Sci. 2017, 18, 2645. [CrossRef] [PubMed]

182. Campos, J.R.; Severino, P.; Ferreira, C.S.; Zielinska, A.; Santini, A.; Souto, S.B.; Souto, E.B. Linseed Essential Oil-Source of Lipids as Active Ingredients for Pharmaceuticals and Nutraceuticals. Curr. Med. Chem. 2019, 26, 4537-4558. [CrossRef] [PubMed]

183. Asadi-Samani, M.; Bahmani, M.; Rafieian-Kopaei, M. The chemical composition, botanical characteristic and biological activities of Borago officinalis: A review. Asian Pac. J. Trop. Med. 2014, 7, S22-S28. [CrossRef]

184. Kasote, D.M.; Zanwar, A.A.; Devkar, S.T.; Hegde, M.V.; Deshmukh, K.K. Immunomodulatory activity of ether insoluble phenolic components of n-butanol fraction (EPC-BF) of flaxseed in rat. Asian Pac. J. Trop. Biomed. 2012, 2, S623-S626. [CrossRef]

185. Park, H.J.; Park, J.S.; Hayek, M.G.; Reinhart, G.A.; Chew, B.P. Dietary fish oil and flaxseed oil suppress inflammation and immunity in cats. Vet. Immunol. Immunopathol. 2011, 141, 301-306. [CrossRef]

186. Che, L.; Zhou, Q.; Liu, Y.; Hu, L.; Peng, X.; Wu, C.; Zhang, R.; Tang, J.; Wu, F.; Fang, Z.; et al. Flaxseed oil supplementation improves intestinal function and immunity, associated with altered intestinal microbiome and fatty acid profile in pigs with intrauterine growth retardation. Food Funct. 2019, 10, 8149-8160. [CrossRef]

187. Hamburger, M.; Riese, U.; Graf, H.; Melzig, M.F.; Ciesielski, S.; Baumann, D.; Dittmann, K.; Wegner, C. Constituents in evening primrose oil with radical scavenging, cyclooxygenase, and neutrophil elastase inhibitory activities. J. Agric. Food Chem. 2002, 50, 5533-5538. [CrossRef] [PubMed]

188. De La Puerta Vazquez, R.; Martinez-Dominguez, E.; Sanchez Perona, J.; Ruiz-Gutierrez, V. Effects of different dietary oils on inflammatory mediator generation and fatty acid composition in rat neutrophils. Metabolism 2004, 53, 59-65. [CrossRef] [PubMed]

189. Yaqoob, P.; Newsholme, E.A.; Calder, P.C. Inhibition of natural killer cell activity by dietary lipids. Immunol. Lett. 1994, 41, 241-247. [CrossRef]

190. Dirks, J.; van Aswegen, C.H.; du Plessis, D.J. Cytokine levels affected by gamma-linolenic acid. Prostaglandins Leukot. Essent. Fatty Acids 1998, 59, 273-277. [CrossRef]

191. Calder, P.C. The effects of fatty acids on lymphocyte functions. Braz. J. Med. Biol. Res. 1993, 26, 901-917. [PubMed]

192. Harbige, L.S. Fatty acids, the immune response, and autoimmunity: A question of n- 6 essentiality and the balance between n-6 and n-3. Lipids 2003, 38, 323-341. [CrossRef]

193. Vangaveti, V.N.; Jansen, H.; Kennedy, R.L.; Malabu, U.H. Hydroxyoctadecadienoic acids: Oxidised derivatives of linoleic acid and their role in inflammation associated with metabolic syndrome and cancer. Eur. J. Pharmacol. 2016, 785, 70-76. [CrossRef]

194. Shewale, S.V.; Boudyguina, E.; Zhu, X.; Shen, L.; Hutchins, P.M.; Barkley, R.M.; Murphy, R.C.; Parks, J.S. Botanical oils enriched in n-6 and n-3 FADS2 products are equally effective in preventing atherosclerosis and fatty liver. J. Lipid Res. 2015, 56, 1191-1205. [CrossRef]

195. Proudman, S.M.; James, M.J.; Spargo, L.D.; Metcalf, R.G.; Sullivan, T.R.; Rischmueller, M.; Flabouris, K.; Wechalekar, M.D.; Lee, A.T.; Cleland, L.G. Fish oil in recent onset rheumatoid arthritis: A randomised, double-blind controlled trial within algorithm-based drug use. Ann. Rheum. Dis. 2015, 74, 89-95. [CrossRef]

196. Vadell, A.K.E.; Bärebring, L.; Hulander, E.; Gjertsson, I.; Lindqvist, H.M.; Winkvist, A. Anti-inflammatory Diet In Rheumatoid Arthritis (ADIRA) - A randomized, controlled crossover trial indicating effects on disease activity. Am. J. Clin. Nutr. 2020, 111, 1203-1213. [CrossRef]

197. Molfino, A.; Amabile, M.I.; Monti, M.; Muscaritoli, M. Omega-3 Polyunsaturated Fatty Acids in Critical Illness: Anti-Inflammatory, Proresolving, or Both? Oxid. Med. Cell. Longev. 2017, 2017. [CrossRef] [PubMed]

198. Lee, A.L.; Park, Y. The association between n-3 polyunsaturated fatty acid levels in erythrocytes and the risk of rheumatoid arthritis in Korean women. Ann. Nutr. Metab. 2013, 63, 88-95. [CrossRef] [PubMed]

199. Sand, I.K. The role of diet in multiple sclerosis: Mechanistic connections and current evidence. Curr. Nutr. Rep. 2018, 7, 150-160. [CrossRef] [PubMed] 
200. Innes, J.K.; Calder, P.C. Omega-6 fatty acids and inflammation. Prostaglandins Leukot. Essent. Fatty Acids 2018, 132, 41-48. [CrossRef] [PubMed]

201. Pischon, T.; Hankinson, S.E.; Hotamisligil, G.S.; Rifai, N.; Willett, W.C.; Rimm, E.B. Habitual dietary intake of n-3 and n-6 fatty acids in relation to inflammatory markers among US men and women. Circulation 2003, 108, 155-160. [CrossRef]

202. Dutta-Roy, A.K.; Demarco, A.C.; Raha, S.K.; Shay, J.; Garvey, M.; Horrobin, D.F. Effects of linoleic and gamma-linolenic acids (efamol evening primrose oil) on fatty acid-binding proteins of rat liver. Mol. Cell. Biochem. 1990, 98, 177-182. [CrossRef]

203. Simon, D.; Eng, P.A.; Borelli, S.; Kägi, R.; Zimmermann, C.; Zahner, C.; Drewe, J.; Hess, L.; Ferrari, G.; Lautenschlager, S.; et al. Gamma-linolenic acid levels correlate with clinical efficacy of evening primrose oil in patients with atopic dermatitis. Adv. Ther. 2014, 31, 180-188. [CrossRef]

204. Veale, D.J.; Torley, H.I.; Richards, I.M.; O’Dowd, A.; Fitzsimons, C.; Belch, J.J.; Sturrock, R.D. A double-blind placebo controlled trial of Efamol Marine on skin and joint symptoms of psoriatic arthritis. Br. J. Rheumatol. 1994, 33, 954-958. [CrossRef]

205. Tomic-Smiljanic, M.; Vasiljevic, D.; Lucic-Tomic, A.; Andjelkovic, N.; Jakovljevic, V.; Bolovich, S.; Veselinovic, M. Influence of different supplementation on platelet aggregation in patients with rheumatoid arthritis. Clin. Rheumatol. 2019, 38, 2443-2450. [CrossRef]

206. Cameron, M.; Gagnier, J.J.; Chrubasik, S. Herbal therapy for treating rheumatoid arthritis. Cochrane Database Syst. Rev. 2011. [CrossRef]

207. Bamford, J.T.; Ray, S.; Musekiwa, A.; van Gool, C.; Humphreys, R.; Ernst, E. Oral evening primrose oil and borage oil for eczema. Cochrane Database Syst. Rev. 2013. [CrossRef] [PubMed]

208. Foster, R.H.; Hardy, G.; Alany, R.G. Borage oil in the treatment of atopic dermatitis. Nutrition 2010, 26, 708-718. [CrossRef] [PubMed]

209. Ursoniu, S.; Sahebkar, A.; Serban, M.C.; Pinzaru, I.; Dehelean, C.; Noveanu, L.; Rysz, J.; Banach, M. Lipid and Blood Pressure Meta-Analysis Collaboration (LBPMC) Group. A systematic review and meta-analysis of clinical trials investigating the effects of flaxseed supplementation on plasma C-reactive protein concentrations. Arch. Med. Sci. 2019, 15, 12-22. [CrossRef] [PubMed]

210. Reuben, J.P. Two rings in them all: The labdane-related diterpenoids. Nat. Prod. Rep. 2010, 27, 1521-1530.

211. Dai, Y.; Chen, S.R.; Chai, L.; Zhao, J.; Wang, Y.; Wang, Y. Overview of pharmacological activities of Andrographis paniculata and its major compound andrographolide. Crit. Rev. Food Sci. Nutr. 2018, 59, S17-S29. [CrossRef]

212. Singh, S.; Kumar, J.K.; Saikia, D.; Shanker, K.; Thakur, J.P.; Negi, A.S.; Banerjee, S. A bioactive labdane diterpenoid from Curcuma amada and its semisynthetic analogues as antitubercular agents. Eur. J. Med. Chem. 2010, 45, 4379-4382. [CrossRef]

213. Yang, Z.; Wang, Q.; Peng, W.; Zhan, R.; Chen, Y. A new 12,17-cyclo-labdane diterpenoid from the twigs of Dacrycarpus imbricatus. Nat Prod Res. 2018, 32, 1669-1675. [CrossRef]

214. Kobayashi, J.; Sekiguchi, M.; Shigemori, H.; Ohsaki, A. Chapecoderins A-C, new labdane-derived diterpenoids from Echinodorus macrophyllus. J. Nat. Prod. 2000, 63, 375-377. [CrossRef]

215. Qiao, Y.; Khutsishvili, M.; Alizade, V.; Atha, D.; Borris, R.P. Labdane and Abietane Diterpenoids from Juniperus oblonga and Their Cytotoxic Activity. Molecules 2019, 24, 1561. [CrossRef]

216. Zhang, R.-H.; Liu, Z.-K.; Yang, D.-S.; Zhang, X.-J.; Sun, H.-D.; Xiao, W.-L. Phytochemistry and pharmacology of the genus Leonurus: The herb to benefit the mothers and more. Phytochemistry 2018, 147, 167-183. [CrossRef]

217. Tran, Q.T.N.; Wong, W.S.F.; Chai, C.L.L. Labdane diterpenoids as potential anti-inflammatory agents. Pharmacol. Res. 2017, 124, 43-63. [CrossRef] [PubMed]

218. Ban, N.K.; Thoa, N.T.K.; Linh, T.M.; Trang, D.T.; Van Kiem, P.; Nhiem, N.X.; Tai, B.H.; Van Minh, C.; Song, J.-H.; Ko, H.-J.; et al. Labdane-type diterpenoids from Vitex limonifolia and their antivirus activities. J. Nat. Med. 2018, 72, 290-297. [CrossRef] [PubMed]

219. Hu, X.Y.; Wu, R.H.; Logue, M.; Blondel, C.; Lai, L.; Stuart, B.; Flower, A.; Fei, Y.T.; Moore, M.; Shepherd, J.; et al. Andrographis paniculata (Chuān Xīn Lián) for symptomatic relief of acute respiratory tract infections in adults and children: A systematic review and meta-analysis. PLoS ONE 2017, 12, e0181780. [CrossRef] [PubMed] 
220. Islam, M.T.; Ali, E.S.; Uddin, S.J.; Islam, M.A.; Shaw, S.; Khan, I.N.; Saravi, S.; Ahmad, S.; Rehman, S.; Gupta, V.K.; et al. Andrographolide, a diterpene lactone from Andrographis paniculata and its therapeutic promises in cancer. Cancer Lett. 2018, 420, 129-145. [CrossRef]

221. Vaz, M.S.M.; Da Silva, M.S.V.; Oliveira, R.J.; Mota, J.D.S.; Brait, D.R.H.; De Carvalho, L.N.B.; Vani, J.M.; Berno, C.R.; Araújo, F.H.S.; De Barros, M.E. Evaluation of the toxicokinetics and apoptotic potential of ethanol extract from Echinodorus macrophyllus leaves in vivo. Regul. Toxicol. Pharmacol. 2016, 82, 32-38. [CrossRef]

222. Da Silva, G.P.; Fernandes, D.C.; Vigliano, M.V.; da Fonseca, E.N.; Santos, S.V.; Marques, P.R.; Justo, M.D.; Sabino, K.C.; Coelho, M.G. Flavonoid-enriched fraction from Echinodorus macrophyllus aqueous extract exhibits high in-vitro and in-vivo anti-inflammatory activity. J. Pharm. Pharmacol. 2016, 68, 1584-1596. [CrossRef]

223. Pinto, A.C.; Rego, G.C.G.; Siqueira, A.M.; Cardoso, C.C.; Reis, P.A.; Marques, E.A.; Coelho, M.G.; Sabino, K.G.C. Immunosuppressive effects of Echinodorus macrophyllus aqueous extract. J. Ethnopharmacol. 2007, 111, 435-439. [CrossRef]

224. Heinrich, M.; Appendino, G.; Efferth, T.; Fürst, R.; Izzo, A.A.; Kayser, O.; Pezzuto, J.M.; Viljoen, A. Best practice in research-Overcoming common challenges in phytopharmacological research. J. Ethnopharmacol. 2020, 246, 112230. [CrossRef]

225. Izzo, A.A.; Teixeira, M.; Alexander, S.; Cirino, G.; Docherty, J.R.; George, C.H.; Insel, P.A.; Ji, Y.; Kendall, D.A.; Panattieri, R.A.; et al. A practical guide for transparent reporting of research on natural products in the British Journal of Pharmacology: Reproducibility of natural product research. Br. J. Pharmacol. 2020, 177, 2169-2178. [CrossRef]

226. Moher, D.; Liberati, A.; Tetzlaff, J.; Altman, D.G.; PRISMA Group. Preferred reporting items for systematic reviews and meta-analyses: The PRISMA statement. Int. J. Surg. 2010, 8, 336-341. [CrossRef]

(C) 2020 by the authors. Licensee MDPI, Basel, Switzerland. This article is an open access article distributed under the terms and conditions of the Creative Commons Attribution (CC BY) license (http://creativecommons.org/licenses/by/4.0/). 